\title{
Synoptic Variability of Ocean-Atmosphere Turbulent Fluxes Associated with Atmospheric Cyclones
}

\author{
Olga ZolinA \\ Meteorologisches Institut, Universitaet Bonn, Bonn, Germany, and P. P. Shirshov Institute of Oceanology, RAS, Moscow, Russia \\ Sergey K. Gulev \\ P. P. Shirshov Institute of Oceanology, RAS, Moscow, Russia, and Institut fuer Meereskunde, Kiel, Germany
}

(Manuscript received 8 October 2001, in final form 3 March 2003)

\begin{abstract}
Synoptic-scale variability in the air-sea turbulent fluxes in the areas of midlatitudinal western boundary currents is analyzed. In the Gulf Stream area, ocean-atmosphere fluxes on synoptic time- and space scales are clearly coordinated with the propagating synoptic-scale atmospheric transients. The statistical analysis of 6-hourly resolution sea level pressure and surface turbulent fluxes from the NCEP-NCAR reanalysis for the period from 1948 to 2000 in the area of strong sea surface temperature gradients in the Gulf Stream gives strong proof for the association between the propagating cyclones and synoptic patterns of surface turbulent fluxes. It is shown that sea-air interaction in this area is controlled by the sharpness of surface temperature gradients in the ocean and by the intensity of the advection of the air masses in different parts of cyclones during the cold-air and warm-air outbreaks. A simple parameter based on the joint consideration of the characteristics of sea surface temperature and sea level pressure fields is used to characterize the synoptic variability of air-sea turbulent fluxes. The effectiveness of the relationship between surface temperature and surface pressure on one side and air-sea flux anomalies on the other vary from year to year in phase with variability in the frequencies of deep atmospheric cyclones in the Gulf Stream area. The limits of applicability of the approach, its sensitivity to higher-resolution sea surface temperature data, and the possibility of its further applications are discussed.
\end{abstract}

\section{Introduction}

Regions of the western boundary currents (Gulf Stream and Kuroshio) are characterized by the highest latent and sensible climatological air-sea fluxes and their very intensive variability on both synoptic and interannual timescales. Sea-air exchange in these areas provides a diabatic heating of the lower atmosphere and may cause atmospheric circulation anomalies in the midlatitudes. The close link between the anomalies of the ocean-atmosphere surface fluxes and atmospheric circulation in the midlatitudes was diagnosed in many experimental and model studies. Cayan (1992a,b,c) first depicted the leading modes of sea-air flux interannual variability and found their association with sea surface temperature (SST) and atmospheric circulation anomalies. He found that the North Atlantic Oscillation (NAO) pattern in the sea level pressure (SLP) is closely associated with the subtropical-subpolar dipole in the surface turbulent flux anomalies with the centers of ac-

Corresponding author address: Olga Zolina, Meteorologisches Institut, Universitaet Bonn, Auf dem Hugel, 20, D-53121 Bonn, Germany.

E-mail: olga.zolina@uni-bonn.de tion over the Gulf Stream and in the northwest Atlantic. These results were later confirmed by different authors, using various data and analysis techniques (e.g., Iwasaka and Wallace 1995; Gulev et al. 2003, manuscript submitted to J. Phys. Oceanogr., hereafter GJR). Cayan (1992a) argued that the interannual anomalies of seaair fluxes over the Gulf Stream are correlated with the northwest wind directions and hypothesized that association between surface fluxes and atmospheric circulation should have a link to the North Atlantic midlatitudinal storminess.

However, accurate knowledge of sea-air turbulent exchange and understanding the mechanisms of the largescale ocean-atmosphere interaction in the areas of western boundary currents requires analysis of air-sea fluxes and atmospheric transients on synoptic timescales. Indeed, it is the highly variable surface flux and not the mean flux field, that forms the actual signal at the seaair interface. The highest space-time synoptic variability of air-sea fluxes is observed in the midlatitudes. Spatial variability here is controlled by the sharp spatial gradients of SST in the Gulf Stream and Kuroshio regions. Temporal variability is driven by highly variable winds and airmass properties, associated with the mid- 
latitudinal cyclones. According to the case studies (e.g., Petterson et al. 1962; Yau and Jean 1989; Gulev and Tonkacheev 1996; WGASF Group 2000; Giordani and Caniaux 2001), synoptic space-time variations of surface turbulent fluxes can vary within several hundreds and even thousands of watts per squared meter.

The mechanism responsible for the intensified cyclone activity over the SST front is the differential modification of the atmospheric boundary layer (ABL) associated with local ageostrophic circulations and other factors. Wai (1988) and Wai and Stage (1989) demonstrated that the structure of marine ABL over the Gulf Stream could be considerably changed under the advection of different directions. Mak (1998) showed that the self-induced surface sensible heat flux might enforce the baroclinic instability and provoke incipient marine cyclogenesis. Giordani and Caniaux (2001) argued that the existence of the sharp SST front is critical for the modification of ABL in the propagating cyclone. These results were supported by several observational studies of cold-air outbreaks over the SST fronts (e.g., Sethuraman et al. 1986; Bane and Osgood 1989; Yau and Jean 1989; Friehe et al. 1991; Chang et al. 1987; Chao 1992; Reddy and Raman 1994; Gulev and Tonkacheev 1996, and others). Similar processes over the ice margins and the coast lines were studied by Overland et al. (1983), Konrad and Colucci (1989), and Okland (1998). Warmair outbreaks, responsible for the modification of ABL in the case of the advection of warm air over a coldwater area were analyzed by Hsu (1983) and Neiman et al. (1990). At the same time, some works suggest that surface fluxes reduce the low-level baroclinicity and thus, can abate cyclogenesis (e.g., Nuss and Anthes 1987). Despite the discussion on whether extreme fluxes in the regions of strong SST gradients (and, thus, differential heating) provide an intensification of the propagating and generation of new cyclones, or, alternatively, decrease cyclone activity, an association of the local extremes of air-sea fluxes with enhanced storm track activity is quite evident.

Further (with respect to the case studies) analysis of synoptic sea-air interaction requires high-resolution data about air-sea fluxes. Variability of the ocean-atmosphere fluxes on synoptic timescales is poorly known, due to the lack of high-resolution data to quantify fast interhourly to interdaily changes in the surface flux fields. Zorita et al. (1992) used intramonthly statistics derived from voluntary observing ship (VOS) data for the analysis of the intensity of synoptic variability. However, VOS data are sampled irregularly in space and time and do not allow for the separation of sampling errors and natural synoptic variability. Miller and Katsaros (1992) used Special Sensor Microwave Imager (SSM/I) measurements for the diagnostics of air-sea flux variability associated with marine cyclones. However, high-resolution satellite data still have limited continuity in time and need to be validated. Alexander and Scott (1997) first analyzed the association of sea- air turbulent fluxes with propagating atmospheric transients on synoptic timescales, using 17-yr output with daily resolution from an atmospheric general circulation model (GCM). They found that synoptic anomalies of surface turbulent fluxes in the North Atlantic and North Pacific midlatitudes propagate, following the atmospheric midlatitudinal storms. Highly positive flux anomalies (positive fluxes are directed from the ocean to the atmosphere) were identified in the western parts of the atmospheric storms and the eastern parts of the storms were associated with the negative anomalies of the turbulent fluxes. These results are in agreement with many case studies and suggest a close association between the atmospheric cyclones and surface turbulent fluxes in the midlatitudes on synoptic timescales. This effect may have climatological implications. A number of authors showed close association between the largescale SST gradients and climatological cyclone activity (Dickson and Namias 1976; Harnack and Broccoli 1979; Lanzante 1983; Lambert 1996). Hoskins and Valdes (1990) argued that diabatic heating is very important for the maintenance of large-scale baroclinicity. Recently, Gulev et al. (2002) showed that SST gradients together with land-sea temperature differences are largely responsible for the variability of the storm tracks in the northwest Atlantic.

The aim of this work is to diagnose the association between surface turbulent fluxes and atmospheric synoptic transients in the Gulf Stream area on the basis of 6-hourly National Centers for Environmental Prediction-National Center for Atmospheric Research (NCEP-NCAR) reanalysis data (Kalnay, et al. 1996; Kistler et al. 2001). These data together with the European Centre for Medium Range Weather Forecasts (ECMWF) Re-Analysis (ERA-15; Gibson et al. 1997) represent the only source of the long-term high-resolution flux time series at present. We will try to analyze the relationships between the atmospheric cyclones and air-sea turbulent exchange in order to show a link between air-sea flux synoptic variability and variations in the SST and SLP fields, which are more easily available and more accurate in comparison to the surface fluxes. This gives the possibility of the long-term monitoring of synoptic variability in sea-air turbulent fluxes over the western boundary currents.

\section{Data}

In this study we used 6-hourly data from the NCEPNCAR reanalysis (Kalnay et al. 1996; Kistler et al. 2001) for the period from 1948 to 2000. Surface sensible and latent heat fluxes, as well as SST were used at $1.875^{\circ}$ $X \approx 1.9^{\circ}$ spatial resolution (the so-called Gaussian grid) and SLP data had $2.5^{\circ} \times 2.5^{\circ}$ spatial resolution in the midlatitudinal North Atlantic from $25^{\circ}$ to $60^{\circ} \mathrm{N}$. Turbulent fluxes in the NCEP-NCAR reanalysis are 6-hourly averages computed from the 6-hourly forecasts of basic variables by the NCEP T62 operational model 

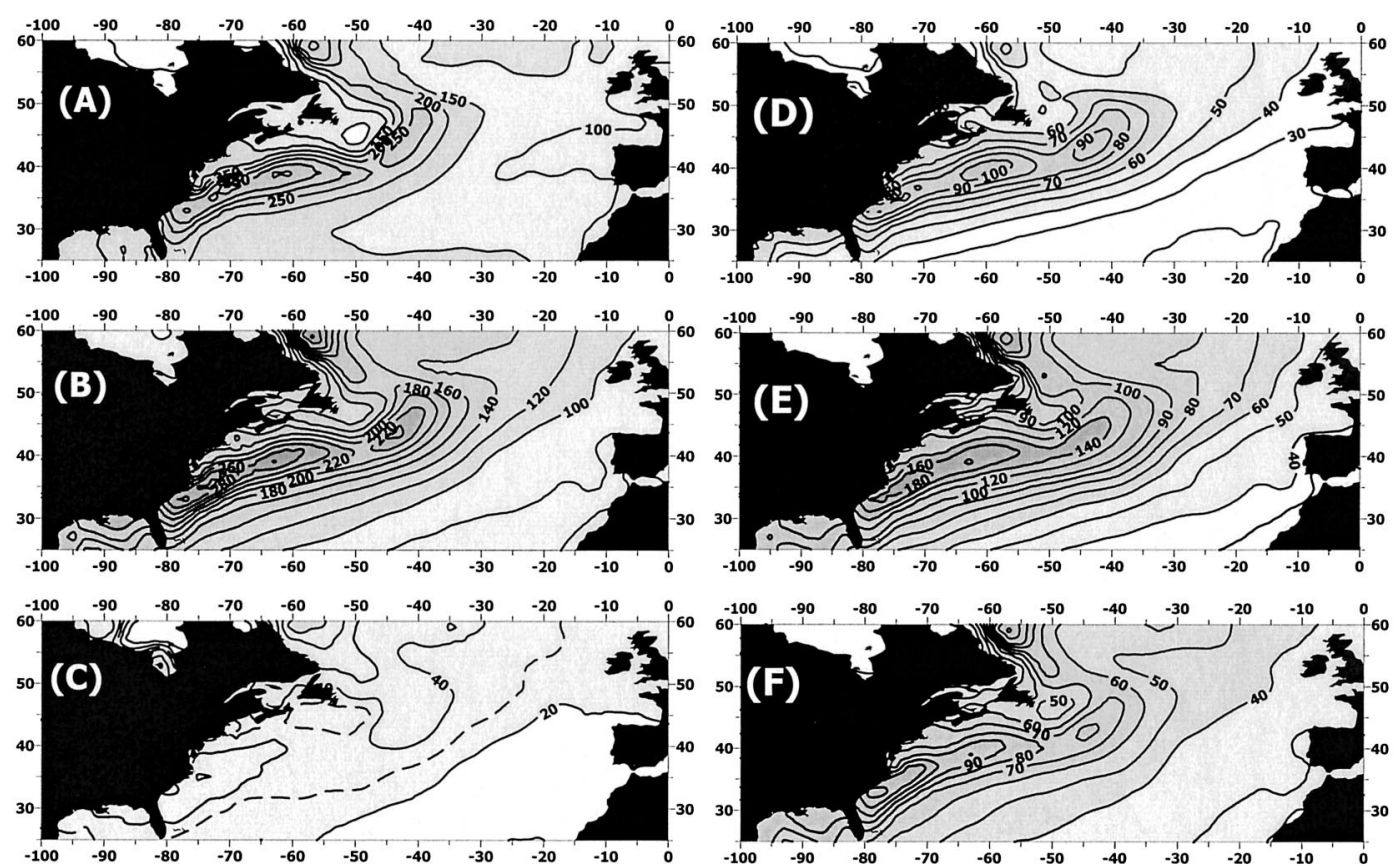

FIG. 1. Climatological winter (JFM) sensible plus latent heat flux $\left(\mathrm{W} \mathrm{m}^{-2}\right)$ derived from the NCEP-NCAR reanalysis (a) averaged over 53 winters (1948-2001), (b) synoptic std dev of the sensible plus latent heat flux, (c) interannual winter std dev of the sensible plus latent heat flux, and std dev for the bandpassed time series of the sensible plus latent heat fluxes for synoptic ranges of (d) 0-2, (e) 2-6, and (f) 6-12 days.

(Kalnay et al. 1996). Atmospheric boundary layer formulation of Long (1988), based on the bulk formulas, was used to compute turbulent fluxes. For the further analysis sensible and latent heat fluxes as well as SLP from the NCEP-NCAR reanalysis were reinterpolated onto $2^{\circ} \times 2^{\circ}$ grid, using the modified method of local procedures of Akima (1970).

To depict the SST gradients in the Gulf Stream we used SST fields available from the NCEP-NCAR reanalysis. According to Kalnay et al. (1996), they are represented by the optimum interpolation (OI) SST of Reynolds and Smith (1994), which originally had weekly resolution and were interpolated on 6-hourly time steps. Spatial resolution of the SST fields may be crucial for the reliable estimation of the frontal gradients. Particularly, Eymard et al. (1999) and Giordani and Caniaux (2001) argued that the SST fields available from the operational analyses and reanalyses in this region may require adjustment in order to better locate the SST front. For the analysis of sensitivity of our results to the spatial resolution of the SST data we additionally analyzed for selected years high-resolution multichannel SST (MCSST) fields derived from the National Oceanic and Atmospheric Administration (NOAA) Advanced Very High Resolution Radiometer (AVHRR). Although these data may have systematic biases with respect to the in situ SST measurements (e.g., Brown et al. 1993), they are very effective for the depiction of the spatial temperature gradients.

In order to quantify the variability in atmospheric cyclogenesis we used the results of the storm tracking performed for the period from 1948 to 2000 on the basis of the 6-hourly NCEP-NCAR reanalysis SLP fields. Cyclone trajectories were produced using a numerical scheme (Zolina et al. 2003, manuscript submitted to Mon. Wea. Rev., hereafter ZGSS), developed on the basis of the archive of storm tracks for the 42 winter seasons (1958-99; Gulev et al. 2001), obtained using the software of Grigoriev et al. (2000). This software is based on the computer analysis of the SLP fields and simulates the manual procedure, making it faster and less dependent on the subjective view and mistakes of a particular operator. In general the numerical scheme follows the method of Murray and Simmonds (1991), but includes dynamic interpolation of the SLP fields. The numerical method of ZGSS shows very good agreement with the results of the semimanual tracking of Gulev et al. (2001). The output of the tracking (coordinates, time, and corresponding SLP values) was used to locate cyclone trajectories and to compute cyclone frequencies, using the mapping procedure of Zolina and Gulev (2002), which minimizes the biases in cyclone counts for the latitude-longitude cells.

\section{Intensity of surface flux variability for different synoptic ranges}

Figure 1 shows the general characteristics of the synoptic variability of air-sea turbulent fluxes in the midlatitudinal North Atlantic for the winter season [Janu- 
ary-February-March (JFM)] from 1948 to 2000. The highest climatological winter sensible plus latent heat fluxes of about $400 \mathrm{~W} \mathrm{~m}^{-2}$ (100 and $300 \mathrm{~W} \mathrm{~m}^{-2}$ for sensible and latent fluxes, respectively) are observed over the Gulf Stream and the North Atlantic Current (Fig. 1a), where they are 3-5 times higher than in the open ocean regions. These patterns qualitatively agree well with climatological distributions from the VOS air-sea flux climatologies (e.g., da Silva et al. 1994a,b,c,d,e,f; Josey et al. 1999), which can demonstrate quantitatively different magnitudes of fluxes, which are determined by the parameterizations and variable corrections used in the VOS climatologies (e.g., Josey et al. 1999; GJR). In order to analyze synoptic variability in surface turbulent fluxes, we consider surface heat flux synoptic anomalies, assuming that the observed sensible $\left(Q_{h}\right)$ and latent $\left(Q_{e}\right)$ heat fluxes are represented by the mean, corresponding to, say, monthly averaged fluxes in each grid point, and the anomalies, which are estimated around this monthly mean:

$$
Q_{h}=\bar{Q}_{h}+Q_{h}^{\prime}, \quad Q_{e}=\bar{Q}_{e}+Q_{e}^{\prime},
$$

where the overbar corresponds to the monthly mean and the prime stands for the synoptic anomalies. Magnitudes of synoptic variability in sea-air turbulent fluxes, characterized by the synoptic standard deviations (std dev) of sensible plus latent fluxes average over 53 winter seasons (1948-2000), are 250-350 $\mathrm{W} \mathrm{m}^{-2}$ (Fig. 1b); these are approximately of the same order as the mean flux values and may vary within $\pm 10 \%-15 \%$ from year to year. Magnitudes of synoptic variability in sea-air fluxes in this area are approximately 3-5 times higher than interannual variability, characterized by the interannual std dev (Fig. 1c), which vary from 40 to $60 \mathrm{~W}$ $\mathrm{m}^{-2}$. The depicted features are observed during all seasons (not shown here).

For further analysis we performed the bandpassing of the original 6-hourly time series of SLP and surface sensible $\left(Q_{h}\right)$, latent $\left(Q_{e}\right)$, as well as sensible plus latent $\left(Q_{h e}\right)$ heat fluxes for different synoptic subranges. We analyzed timescales from $6 \mathrm{~h}$ to 2 days [the so-called ultrahigh frequency variability (UHFV)]; 2-6 days, corresponding to synoptic-scale transients (SSCV); 6-12 days, associated with the slow synoptic processes (SSP); and 12-30 days, known as the low-frequency variability (LFV). Such a breakdown agrees well with previous the studies of Blackmon et al. (1984), Ayrault et al. (1995), Gulev (1997), and Gulev et al. (2002), who reported differences in spatial patterns and interannual variability between different synoptic subranges. Alexander and Scott (1997) considered ranges between 3-10 and 1030 days. However, they analyzed daily model data. Bandpass filtering has been performed using the Lanczos filter (Lanczos 1956; Duchon 1979), used earlier for the analysis of synoptic variability by Hoskins and Sardeshmukh (1987), Alexander and Scott (1997), Gulev (1997), and Gulev et al. (2002). This filter has a very effective cutoff at a selected frequency, which is important for the consideration of neighboring ranges. Gibbs oscillations, produced by the Lanczos filtering, were reduced by the smoothing in the frequency range. Filtering has been performed for the seasonal time series, which allows for the application of the Lanczos window, resulting in a 20-day cutoff of the original time series.

If we consider the individual synoptic ranges, the largest magnitudes of variability of sensible plus latent fluxes are about $200 \mathrm{~W} \mathrm{~m}^{-2}\left(30-80\right.$ and $70-120 \mathrm{~W} \mathrm{~m}^{-2}$ for sensible and latent fluxes, respectively) and associated with the range of 2-6 days (Fig. 1e). The intensities of UHFV and SSPV (Figs. 1d,f) in the turbulent fluxes are approximately 2 times weaker and in the Gulf Stream area range from 80 to $100 \mathrm{~W} \mathrm{~m}^{-2}$. Magnitudes of the low-frequency variability (not shown) are 2.5-3 times smaller than those for SSCV. In general, the ratios between the magnitudes of synoptic and low-frequency variability of the surface turbulent fluxes obtained from the NCEP-NCAR reanalysis agree well with the results of Alexander and Scott (1997), who reported 10-30 days of variability to be approximately 3 times weaker with respect to the variability in the range of 3-10 days from the daily model data.

\section{Association of the propagating SLP and surface turbulent flux patterns on the synoptic timescale in the North Atlantic midlatitudes}

Alexander and Scott (1997) used EOFs to identify the propagating patterns in the filtered SLP and surface flux fields. Figure 2 shows the first two EOFs of the bandpassed SLP and sensible-plus-latent heat fields for the ranges corresponding to UHFV and SSCV ( $0-2$ and 2-6 days). For these ranges, the first two EOFs of SLP show similar patterns, which are in quadrature and are represented by the four to five (for UHFV) and by three to four (for SSCV) centers with alternating signs. For UHFV the first two EOFs explain 19\% and $16 \%$ of the total variance; the corresponding percentages for SSCV are $28 \%$ and $23 \%$. Cross-correlation function between the first and the second normalized principal components (Fig. 3) clearly indicates phase lags of about 6$12 \mathrm{~h}$ (for UHFV) and 18-24 $\mathrm{h}$ (for SSCV). For the range of 2-6 days this yields the propagation of synoptic transients along the North Atlantic midlatitudinal storm track with an approximate velocity of $40-60 \mathrm{~km} \mathrm{~h}^{-1}$ for a typical spatial scale ranging from 1600 to 2400 $\mathrm{km}$. For the range of UHFV the corresponding estimates give from 50 to $70 \mathrm{~km} \mathrm{~h}^{-1}$ for typical spatial scales of 900-1300 km. These propagation velocities are in agreement with independent estimates obtained from the analysis of cyclone propagation (e.g., Zolina and Gulev 2002).

If we consider the first two EOFs of the $Q_{h e}$ field for the same ranges (Figs. 2e-h), their structure will be very similar to that observed for the SLP. The first two EOFs of the sensible and latent fluxes explain $12 \%$ and $9 \%$ 

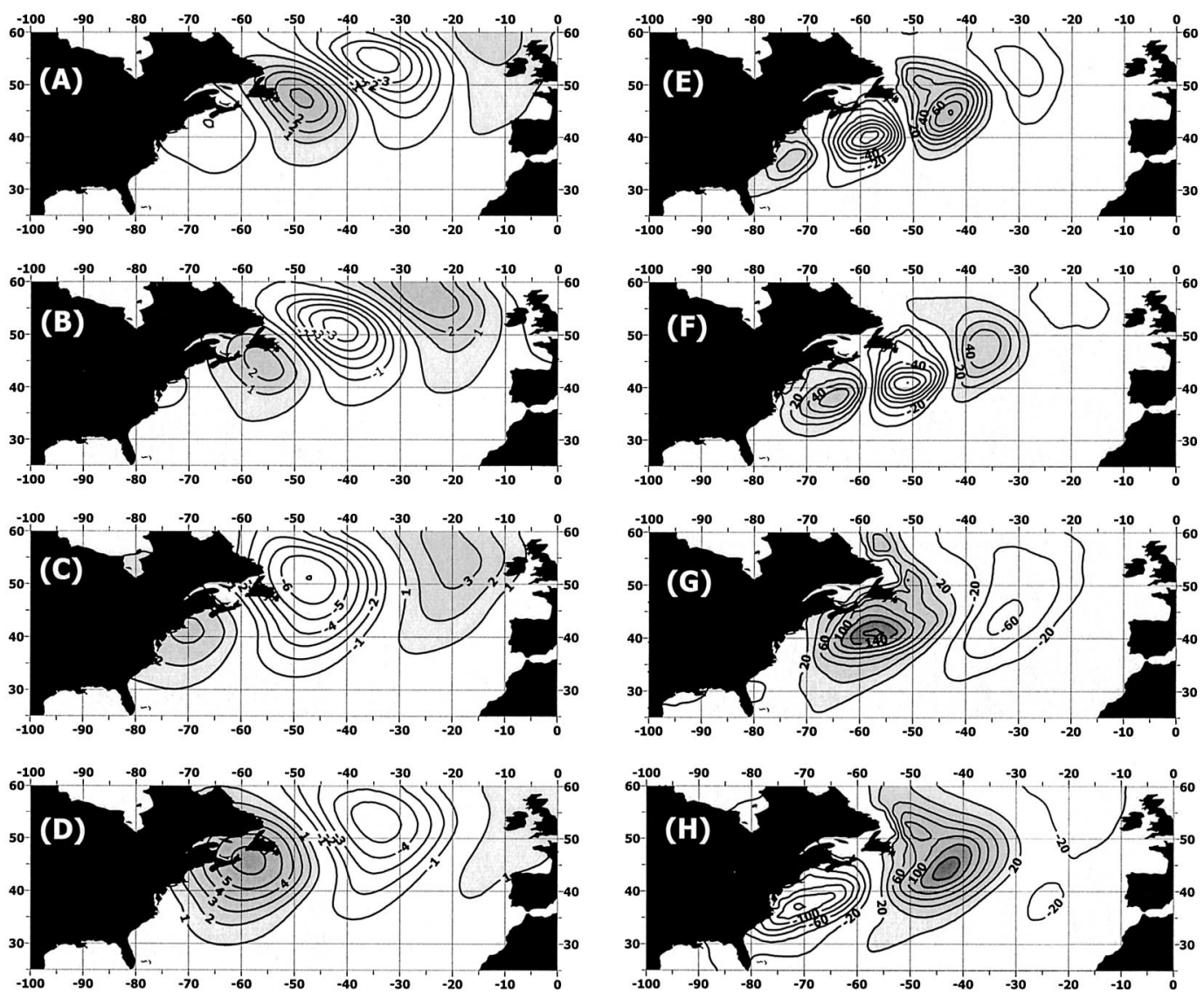

FIG. 2. (a), (c), (e), (g) First and (b), (d), (f), (h) second EOFs of the (a)-(d) SLP (hPa) and (e)-(h) sensible plus latent heat flux anomaly $\left(\mathrm{W} \mathrm{m}^{-2}\right)$ for synoptic ranges of (a), (b), (e), (f) 0-2 and (c), (d), (g), (h) 2-6 days.

of variance for UHFV and $22 \%$ and $17 \%$ of variance for SSCV and show several centers with an alternating sign aligning from the southwest to the northeast. Although centers of action of the spatial patterns for SLP are located 500-600 km north of the corresponding centers of action for $Q_{h e}$, the spatial scales are very similar. Cross-correlation functions between the first two normalized PCs of the $Q_{h e}$ (Fig. 3) nearly coincide with those for the SLP for both UHFV and SSCV, implying that the propagation of the turbulent flux anomalies are coordinated with the SLP anomalies. Alexander and Scott (1997) obtained quite similar results analyzing daily data from a $17-y r$ model run. For the range from 3 to 10 days they obtained somewhat larger spatial scales of the flux anomalies and the maximum of the cross-correlation function between the first two EOFs at a lag of 1 day. Alexander and Scott (1997) collocated the propagating SLP patterns and synoptic anomalies of surface fluxes by performing the composites of SLP and $Q_{h e}$, which were assembled for the magnitudes of SLP anomalies in the selected base point, exceeding $1 \sigma$. For the North Atlantic they demonstrated an association of the positive anomalies of turbulent fluxes with the back parts of cyclones and of the negative anomalies with the cyclones' forward parts.
In order to better identify the SLP and surface turbulent flux patterns optimally correlated with each other we applied canonical correlation analysis (CCA) to the bandpassed SLP and $Q_{h e}$ fields. Figure 4 shows the first canonical correlation patterns between SLP and $Q_{h e}$ for the ranges 0-2 and 2-6 days. Remarkably enough, positive anomalies of surface turbulent fluxes are located in the back parts of synoptic transients in the zone of the strongest pressure gradients, while the forward parts of cyclones are clearly associated with the negative surface flux anomalies. The second canonical patterns (not shown here) identify similar relationship between SLP and heat flux anomalies, being in quadrature to the first ones. Correlation coefficients for the first and the second canonical pairs are equal: 0.96 and 0.90 for UHFV and 0.94 and 0.91 for SSCV. It is important to note that the canonical correlation coefficients for the ranges of SSPV and LFV are much smaller than those for UHFV and SSCV and the canonical correlation analysis (no figure shown) exhibits the patterns associated with the advection of the air from the North American continent to the ocean. This is in contrast to Alexander and Scott (1997), who have found similar associated patterns for the ranges of 3-10 and 10-30 days, if only with different time- and space scales. 

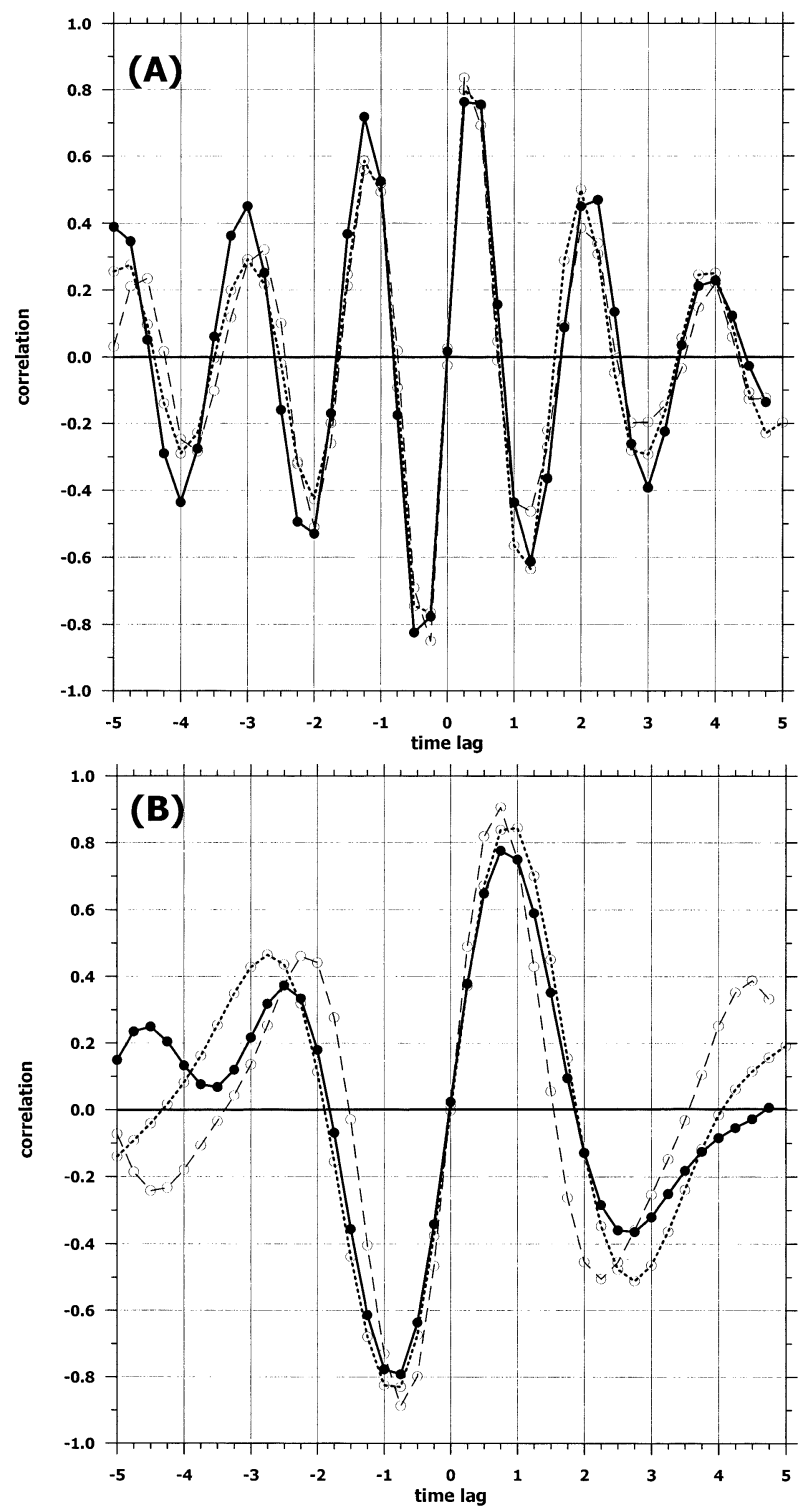

FIG. 3. Cross-correlation functions between the first and the second EOFs of SLP (bold lines), sensible plus latent heat flux anomaly (dashed lines), and the values of the vector product (dotted lines) for synoptic ranges of (a) $0-2$ and (b) 2-6 days.

Spectral analysis of the SLP and surface turbulent flux fields show, for different years, quite variable spectral functions characterized by multiscale synoptic variability (Gulev 1997; Gulev et al. 2002). Spectra for different winters can indicate peaks at somewhat different frequencies with highly variable spectral power. However, for every winter season spectral functions for surface turbulent fluxes and SLP over the Gulf Stream area are very similar to each other and are highly coherent at timescales from 1 to 6-7 days. Figure 5 shows the average cospectrum (over 19 winters 1981-99) of SLP and $Q_{h e}$ for the location $43^{\circ} \mathrm{N}, 51^{\circ} \mathrm{W}$, normalized with respect to the total variance together with the av- eraged over the same winter seasons' coherency and phase lag between the two time series. The cospectrum is represented by a red function with a weak increase of spectral power at 4-5 days. The coherency is quite high for the range from 1 to $6-7$ days, varying from 0.6 to 0.9 . Remarkably enough, phase lag indicates that for the frequency range of 1-6 days, SLP minima lead the maxima of turbulent fluxes by approximately $\pi / 2$ within the storm track. Note here that the spectral characteristics (first of all, phase lag), shown in Fig. 5 remain quite stable within a narrow band of about $500 \mathrm{~km}$ along the Gulf Stream. Note, that there is an indication of the decrease of the phase lag with the growing period. This reflects the fact that for the periods longer than 6-7 days we do not identify coordinated propagation of the SLP and heat flux patterns (in contrast to Alexander and Scott 1997).

We computed the correlation between synoptic anomalies of turbulent fluxes and SLP tendencies (Fig. 6a). Highly positive correlations, ranging from 0.4 to 0.7 , are observed in the Gulf Stream area from Cape Hatteras to approximately $40^{\circ}-45^{\circ} \mathrm{W}$. For the raw time series of synoptic anomalies, the highest positive (negative) SLP tendencies in this region are associated with the strongest positive (negative) synoptic anomalies of surface turbulent fluxes. Outside of the Gulf Stream, correlation decreases sharply to insignificant values, showing that flux anomalies are not associated with the propagating SLP patterns. If we consider the correlation between the SLP tendencies and synoptic turbulent flux anomalies for different scales of synoptic variability (Figs. 6b-e), the highest correlations (up to 0.9) and their clear association with the Gulf Stream area are observed only for UHFV and SSCV (Figs. 6b,c), while for SSPV and LFV relatively high positive correlations are observed over the offshore regions along the North American coast (Figs. 6d,e).

\section{Synoptic variability in surface turbulent fluxes parameterized in terms of SLP and SST fields}

Previous results clearly show that the propagating synoptic transients are associated with the coherent patterns in surface turbulent fluxes, in particular with the positive flux anomalies in the back parts of cyclones and the negative anomalies in the forward parts. On one hand, this is consistent with the advection of the relatively cold and dry air and relatively warm and wet air in the back and the forward parts of cyclones, respectively. On the other hand, SST gradients may play an additional role in driving flux anomalies. Figure 7a shows magnitudes of the spatial gradients of SST together with the number of cyclones with a maximum depth lower than $980 \mathrm{hPa}$ during the winter season. SST gradients were computed from 6-hourly NCEP-NCAR reanalysis SST fields by central differences as 

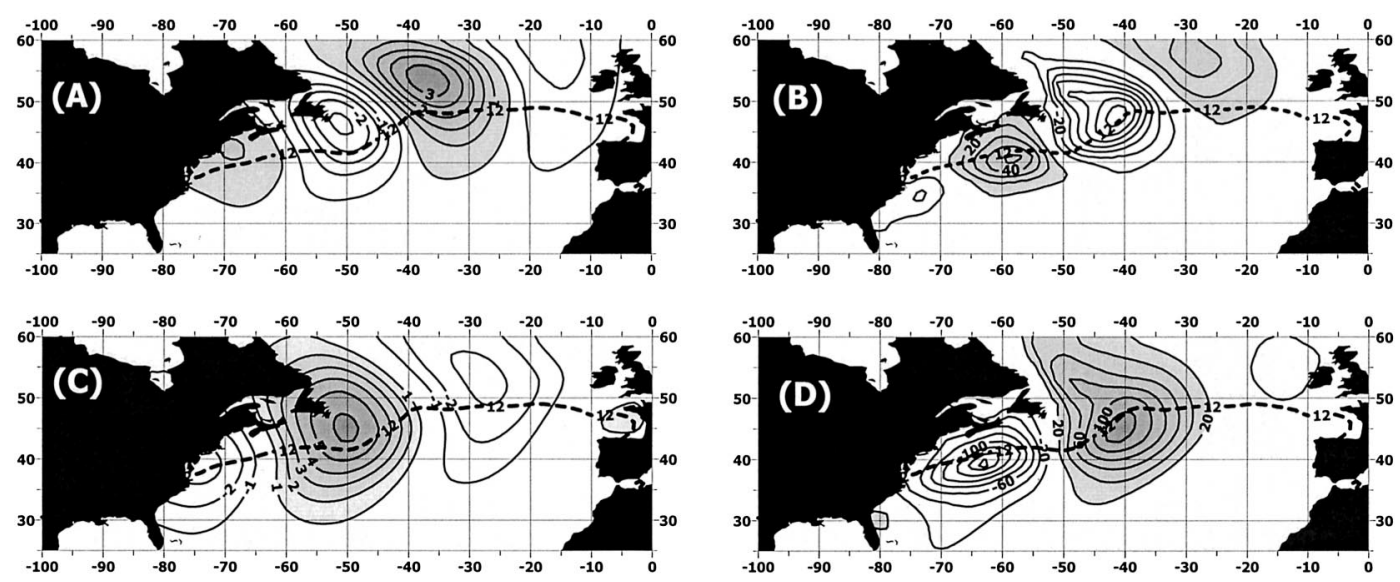

FIG. 4. (a), (c) First canonical patterns of the SLP (hPa) and (b), (d) synoptic anomalies of sensible plus latent heat flux $\left(\mathrm{W} \mathrm{m}^{-2}\right)$ for synoptic ranges of (a), (b), 0-2 and (c), (d) 2-6 days. Bold dashed line shows the location of the $12^{\circ} \mathrm{C}$ SST isotherm associated with the location of the Gulf Stream front.

$$
\frac{\partial \mathrm{SST}}{\partial \mathbf{n}}=\frac{\partial \mathrm{SST}}{\partial x} \mathbf{i}+\frac{\partial \mathrm{SST}}{\partial y} \mathbf{j},
$$

and were averaged over 53 winters. They reasonably mark the zone of high gradients over the Gulf Stream where winter climatological gradients exceed $3^{\circ} \mathrm{C}(100$ $\mathrm{km})^{-1}$. Cyclone numbers have been estimated from the NCEP-NCAR reanalysis cyclone tracks for $2.5^{\circ} \times 2.5^{\circ}$ boxes using the counting method of ZGSS and were normalized with latitude to achieve the comparability of the results for different latitudes. The maximum number of cyclones in the western North Atlantic is clearly

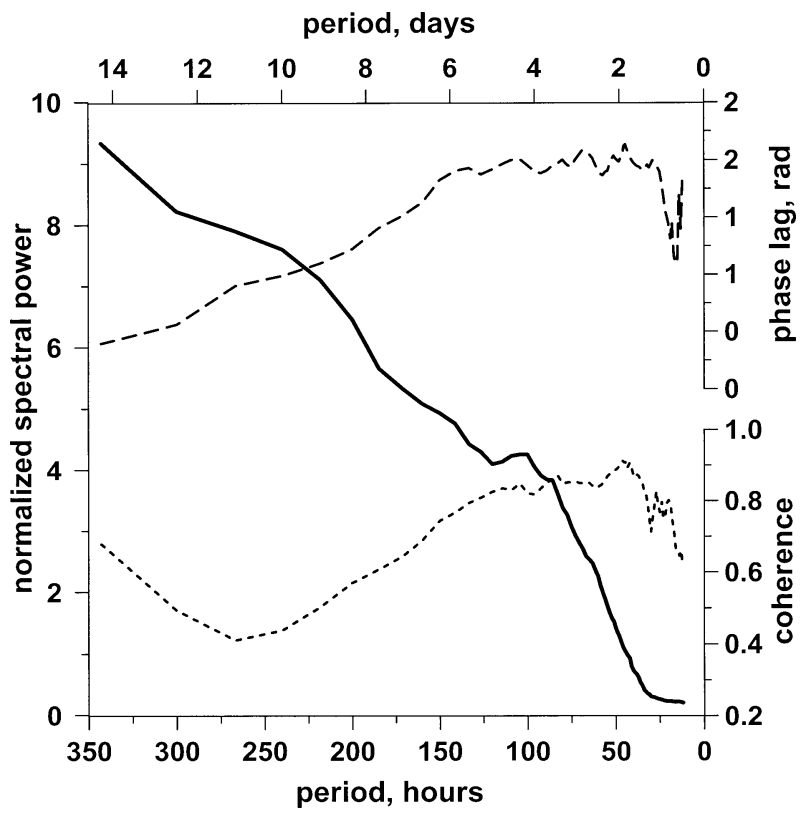

FIG. 5. Normalized cospectrum (bold line), phase lag spectrum (dashed line), and coherence spectrum (dotted line) of the SLP and synoptic anomalies of sensible plus latent heat flux for the location $43^{\circ} \mathrm{N}, 51^{\circ} \mathrm{W}$ averaged over 19 winters (1981-99). associated with the Gulf Stream region, showing the extreme cyclone occurrences over the highest SST gradients.

In the Gulf Stream area, associated with the North Atlantic midlatitudinal storm track, synoptic anomalies of surface turbulent fluxes result from the joint effect of propagating cyclones and strong surface temperature gradients at the sharp SST front. In the back part of the cyclone propagating over the SST front in the Gulf Stream area, cold and dry Arctic air masses are advected over the relatively warm water (cold-air outbreak). In this case the largest sea-air temperature differences are observed over the SST front due to much smoother spatial temperature gradients in the atmosphere in comparison with the ocean. South of the SST front thermodynamic adjustment of airmass properties works to decrease the air-sea temperature and humidity differences. The locally growing fluxes were observed in the case studies of Sethuraman et al. (1986), Bane and Osgood (1989), and Gulev and Tonkacheev (1996). According to Gulev and Tonkaceev (1996) during the coldair outbreak in the nearest vicinity of the Gulf Stream SST front (within $200 \mathrm{~km}$ ) air-sea temperature differences range from 5 to $18 \mathrm{~K}$, decreasing to $2-3 \mathrm{~K}$ at a distance of $400-500 \mathrm{~km}$ south of the SST front. This resulted in a 3-10 times local increase of the surface sensible and latent heat fluxes. In the forward part of cyclone the advection of the moist and warm air (warmair outbreak) results in the local decrease of surface fluxes, associated with the advective fogs and strong vertical motions in the lower 100-200-m layer of the atmosphere. In Fig. 7b we show a hypothetical scheme of the interaction between the atmospheric cyclone and the SST front. It implies that the sharpness of the SST front together with the direction and the velocity of the airmass advection in the surface layer largely determine synoptic variability of air-sea fluxes in the limited area over the western boundary current. The dominant fea- 
tures of synoptic variability of air-sea fluxes can be described in terms of the SST field, representing the characteristics of the SST front and the SLP field, which is responsible for the geostrophic advection in the lower atmosphere. An interaction between these two fields can be quantified by the vector product,

$$
\begin{aligned}
\mathbf{R} & =\left[\mathbf{G}(\nabla \mathrm{SST}) \times \mathbf{V}_{g}(\nabla \mathrm{SLP})\right] \\
& \sim \frac{\partial \mathrm{SLP}}{\partial x} \frac{\partial \mathrm{SST}}{\partial y}-\frac{\partial \mathrm{SLP}}{\partial y} \frac{\partial \mathrm{SST}}{\partial x},
\end{aligned}
$$

where $\mathbf{G}$ represents the vector, associated with the intensity of SST gradient, which can be very roughly interpreted as the measure of the geostrophic velocity in the ocean; $\mathbf{V}_{g}$ is the geostrophic wind in the lower atmosphere; and $x$ and $y$ are the coordinates in the longitudinal and latitudinal directions. Being by definition orthogonal to the ocean surface, vector $\mathbf{R}$ will be positive in the case of the cold-air outbreak and negative in the case of the warm-air outbreak in the chosen lefthand coordinate system. When the geostrophic wind direction is parallel to the SST contours, adjustment of the airmass properties should ideally result to the flux anomalies close to zero, which corresponds to the zero values of the vector product $\mathbf{R}$ of the two parallel vectors. Thus, we do expect that vector $\mathbf{R}$ should effectively characterize synoptic variability of surface turbulent fluxes in the vicinity of the SST front.

Values of the vector product were computed numerically from the reinterpolated 6-hourly NCEP-NCAR SST and SLP fields using the central differences. The vector product in Eq. (3) effectively marks positive and negative anomalies of sensible and latent heat fluxes in the forward and back parts of the propagating cyclones and indicates spatial patterns, which are comparable with the flux anomalies patterns. Figures $8 \mathrm{a}-\mathrm{d}$ show the first two EOFs of the values $\mathbf{R}$, bandpassed for the ranges of $0-2$ and $2-6$ days. They account for $14 \%$ and $12 \%$ of the total variance for UHFV (0-2 days) and $21 \%$ and $17 \%$ of the variance for SSCV (2-6 days), which is very close to the percentages obtained for the turbulent flux anomalies. As in the case with surface fluxes, the propagation is clearly identified by the spatial patterns of the first two EOFs being in quadrature and by the cross-correlation between the first two normalized principal components (Fig. 3), which implies for $\mathbf{R}$ the same time lags, as for the surface flux and SLP disturbances. Canonical correlation analysis (Figs. 8e-h) shows that the optimally correlated patterns of $\mathbf{R}$ and $Q_{h e}$ identify very similar propagating patterns with the surface flux anomalies slightly shifted with respect to the vector product anomalies by $100-300 \mathrm{~km}$ to the south in the direction that is orthogonal to the SST front. Correlation coefficients are higher than 0.95 for the first canonical pair and exceed 0.91 for the second pair for both synoptic ranges.

We computed the correlation coefficients between the values of the vector product in Eq. (3) and surface latent
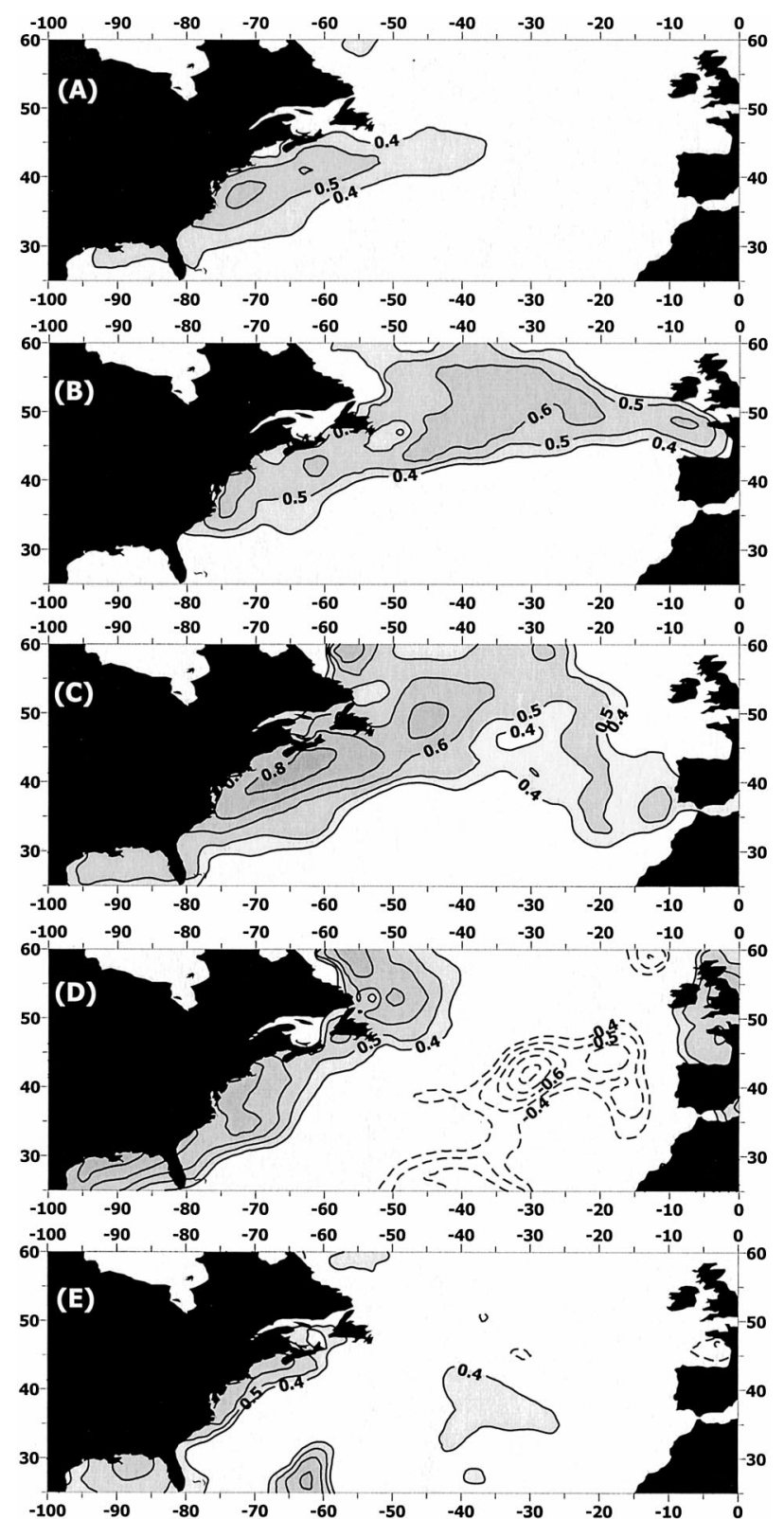

FIG. 6. (a) Correlation coefficients between synoptic anomalies of sensible plus latent heat flux and SLP tendencies for the raw time series of anomalies, and the bandpassed time series for synoptic ranges of (b) 0-2, (c) 2-6, (d) 6-12, and (e) 12-30 days averaged over 53 winters (1948-2000). The $95 \%$ significance level is 0.13 for (a), and 0.16 for the other panels.

and sensible heat flux anomalies in Eq. (1), for different seasons during the period 1948-2000. Figure 9 shows, for example, the maps of the correlation coefficients for the selected year of 1996. The highest correlation coefficients are observed over the Gulf Stream, where they range from 0.6 to 0.8 in winter. In summer the correlation is $10 \%-20 \%$ smaller, but still remains very high. South and north of the area of the SST front and in the open-ocean regions the correlations decrease, showing 

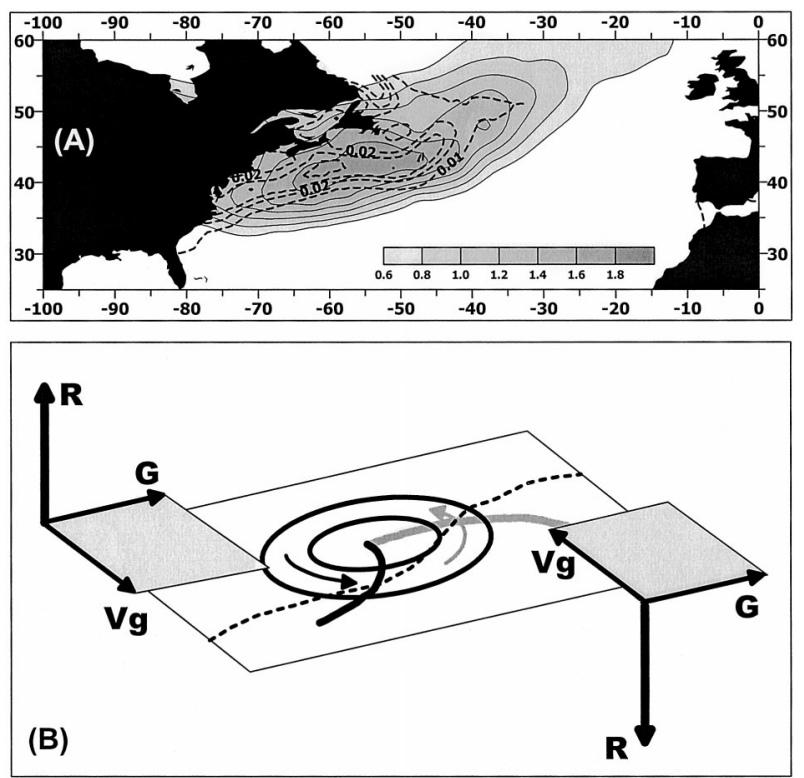

FIG. 7. (a) The magnitude $\left({ }^{\circ} \mathrm{C} \mathrm{km}^{-1}\right)$ of the transfrontal SST gradient [Eq. (2)] averaged over 53 winter seasons (dashed contours) and the spatial distribution of the number of deep cyclones [events per $2.5^{\circ} \times 2.5^{\circ}$ box (gray shading)] and (b) a hypothetical scheme of synoptic air-sea interaction over the Gulf Stream frontal zone in the case of cold-air outbreak and warm-air outbreak.

that the mechanism is only applicable in a limited area of the sharp SST front. Figure 9 is derived for the raw anomalies of fluxes and the vector product. Similar analysis performed for the bandpassed time series (no figure shown) shows the correlation typically exceeding 0.9 in the area of the Gulf Stream front.

Figure 10 demonstrates interannual variability in the correlation coefficients between the vector product and synoptic anomalies of the latent and sensible heat fluxes during the period $1948-2000$ along $50^{\circ} \mathrm{W}$ for the winter and summer seasons. The highest correlation is observed over the Gulf Stream SST front and follows the seasonal migrations in the location of the SST front, indicating the southmost location in winter and the northward shift by approximately $150-250 \mathrm{~km}$ in summer. Correlation remains very high within approximately a $\pm 200-300-\mathrm{km}$ band around the SST front and decreases to the south and to the north. Correlation coefficients vary from 0.6 to 0.9 from year to year. Thus, for the winter season the maximum values were observed during 1976/77, 1983/84, and in the 1990s. Temporal variability in the correlation coefficients is similar for sensible and latent heat fluxes.

The level of correlation between synoptic variability of ocean-atmosphere turbulent fluxes and the values of vector product [Eq. (3)] should be controlled by the number of deep synoptic transients over the Gulf Stream. In order to investigate this link we used the output of the storm tracking over the Northern Hemisphere for the period from 1948 to 2000. Figure 11 shows interannual variability in the winter (JFM) anom- alies of the frequencies of cyclones deeper than $980 \mathrm{hPa}$ (the so-called intense events) in the Gulf Stream area, marked in Fig. 7a, together with the anomalies of the correlation coefficients between the synoptic fluctuations of air-sea turbulent fluxes $\left(Q_{h}^{\prime}+Q_{e}^{\prime}\right)$ and the values of vector product [Eq. (3)]. Anomalies of the cyclone frequencies and correlation coefficients were computed with respect to the mean winter values. Temporal behavior of the cyclone frequencies is fairly consistent with that of the correlation between the vector product and synoptic flux anomalies on both interannual and decadal timescales. Minima in the 1960s, as well as maxima in the mid-1980s and the late 1990s are well marked in both time series. Deep cyclones are typically associated with the high radial pressure gradients and strong winds in the cold sector. The result shown in Fig. 11 agrees with the high correlation between synoptic flux anomalies and SLP tendencies (Figs. 6a-c). We also present in Fig. 11 the anomalies of correlation coefficients between SLP tendencies and fluxes, computed in the same manner as for the correlations between the vector product and fluxes. Remarkably, both curves indicate very similar temporal behavior, which is especially pronounced for the correlation anomalies between the bandpassed UHFV and SSCV ranges of SLP tendencies and fluxes (not shown). However, when a similar analysis was performed for the ranges of SSPV and LVF, time variability becomes quite different, indicating that the mechanism is not working on decadal and longer timescales. Note, that for the frequencies of all cyclones the relationship shown in Fig. 11, is not pronounced. Thus, the deep cyclones over the Gulf Stream are responsible for the effectiveness of the link between the vector product [Eq. (3)] and synoptic anomalies of surface turbulent fluxes.

In order to establish a quantitative link between the values of vector product $\mathbf{R}$ and synoptic sea-air flux anomalies $Q_{h}^{\prime}$ and $Q_{e}^{\prime}$, we analyzed the dependencies between the computed values of $\mathbf{R}$ and the anomalies of fluxes. The overall scatterplot between the vector product $\mathbf{R}$ and synoptic anomalies of sensible plus latent air-sea fluxes $\left(Q_{h}^{\prime}+Q_{e}^{\prime}\right)$ is shown in Fig. 12. This scatterplot indicates somewhat different regression characteristics for the positive and negative values of the vector product, implying higher $\partial Q^{\prime} / \partial \mathbf{R}$ in the positive range. Although the correlation estimated separately for the positive and negative ranges of vector product is quite high $(0.73$ and 0.62 for the positive and negative ranges, respectively), the scatter is largely influenced by the dependency of the ratio between the flux anomaly and the vector product $\left(Q^{\prime} / \mathbf{R}\right)$ on the SST. This is in agreement with Fig. 8 showing the shift between the optimally correlated patterns of the surface fluxes and the vector product $\mathbf{R}$ in the direction orthogonal to the SST front. This shift can be partly associated with a longer-scale adjustment of the lower atmosphere to the ocean over the regions of western boundary currents. Note that in this context, the spatial scales of the anom- 

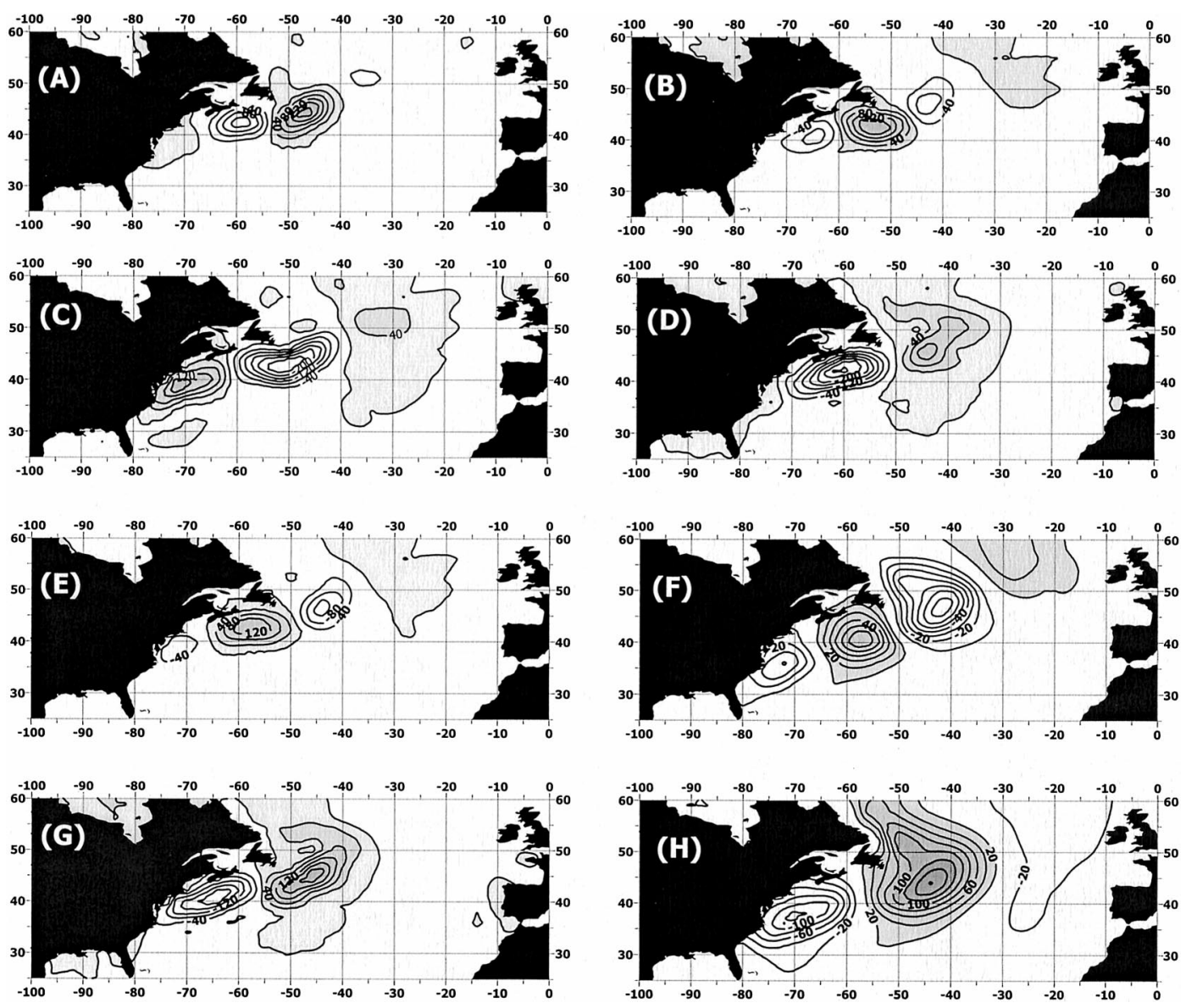

FIG. 8. (a), (c) First and (b), (d) second EOFs of the values of vector product [Eq. (3)] for synoptic ranges of (a), (b) 0-2 and (c), (d) 2-6 days together with (e), (g) the first canonical patterns of the values of the vector product and (f), (h) synoptic anomalies of sensible plus latent heat flux for synoptic ranges of (e), (f) 0-2 and (g), (h) 2-6 days. Values of the vector product are multiplied by 100 .

alies of the vector product are consistent with the flux anomalies in the direction along the SST front and somewhat smaller in the direction orthogonal to the SST front (Fig. 8).

Thus, deriving the regression coefficients, we assumed their slight nonlinear dependency on the local SST. In order to obtain the best fits of $Q_{h}^{\prime}=f(\mathbf{R}, \mathrm{SST})$ and $Q_{e}^{\prime}=f(\mathbf{R}$, SST $)$ we ran an iterative procedure, determining numerical values of the coefficients by the method of least squares separately for the positive and negative values of the vector product. To find the coefficients we only considered the data within the area captured by the local SST gradient 3 times higher than the mean gradient value. The actual values of the maximum SST gradient vary from $1.9^{\circ} \mathrm{C}(100 \mathrm{~km})^{-1}$ in summer to $4.8^{\circ} \mathrm{C}(100 \mathrm{~km})^{-1}$ in winter. This area is associated with an approximately $600-800-\mathrm{km}$ band along the Gulf Stream from Cape Hatteras to $30^{\circ} \mathrm{W}$. Finally the dependencies were obtained in the following general form:

$$
\begin{aligned}
& Q_{h}^{\prime}=A_{h}|\mathbf{R}|=\left(a_{h 0}+a_{h} \mathrm{SST}^{b_{h}}\right)|\mathbf{R}| \times 10^{2}, \\
& Q_{e}^{\prime}=A_{e}|\mathbf{R}|=\left(a_{e 0}+a_{e} \mathrm{SST}^{b_{e}}\right)|\mathbf{R}| \times 10^{2},
\end{aligned}
$$

where the values of the vector product $\mathbf{R}$ are assumed to be in $\mathrm{hPa}{ }^{\circ} \mathrm{C} \mathrm{km}^{-2}$; SST is in degrees Celsius; values of the coefficients $a_{h 0}, a_{h}, b_{h}, a_{e 0}, a_{e}, b_{e}$ together with their variances are given in Table 1 for the positive and negative ranges of the vector product $\mathbf{R}$. The coefficient's variances show that the accuracy of the dependencies (4) is normally better than $10 \%$. Outside of this area the uncertainties expand, indicating that the proposed mechanism is hardly applicable in the open-ocean regions. Dependence of $Q_{h}^{\prime}$ and $Q_{e}^{\prime}$ on the SST in (4) accounts for the shift between the vector product and surface flux anomalies in the direction of the SST gradient and allows the flux anomalies to achieve locally extreme values slightly south of the maximum of SST gradients in agreement with Fig. 8. As it is noted above, relationships (4) and Fig. 12 imply somewhat different dependencies $\partial Q^{\prime} / \partial \mathbf{R}$ for the positive and negative rang- 

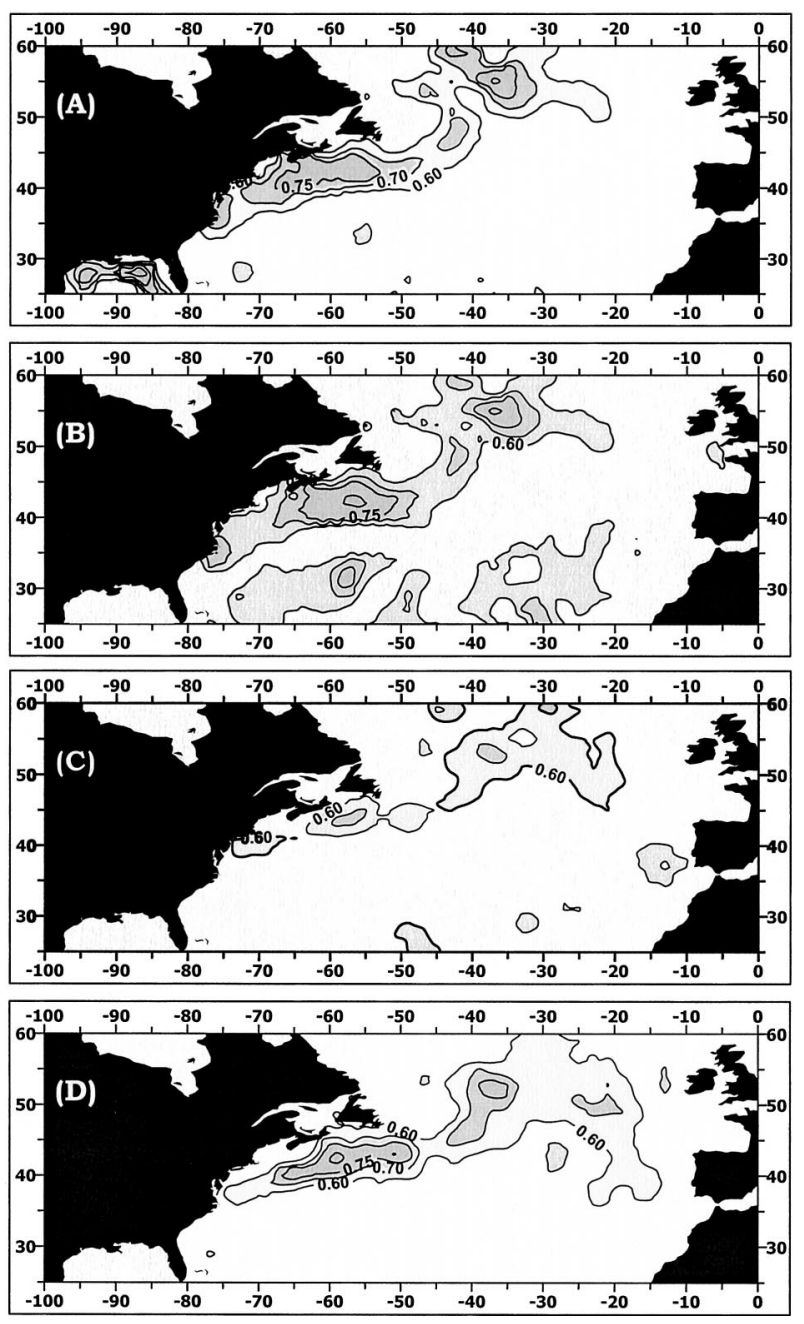

FIG. 9. Maps of the correlation coefficients between the values of vector product [Eq. (1)] and synoptic anomalies of (a), (c) surface latent and (b), (d) sensible fluxes in the North Atlantic midlatitudes for the (a), (b) winter and (c), (d) summer of 1996. A correlation of 0.13 is significant at the $95 \%$ level.

es of R. Although we do not yet have a clear physical explanation, intuitively we think that this is in agreement with a typical distribution of sea-air temperature and humidity differences in midlatitudes, which normally implies much stronger observed positive air-sea temperature differences in comparison to the magnitudes of the negative differences.

Figure 13 shows the results of the application of Eq. (4) to the computation of synoptic variability of air-sea turbulent fluxes in the northwest Atlantic for the winter season of 2001, which was not included in the array for the determination of the coefficients. In order to establish the measure of the effectiveness of the approach we estimated root-mean-square (rms) errors. Then these rms errors were scaled with the standard deviations of synoptic anomalies of sea-air fluxes (Figs. 1c,d) to obtain the relative rms errors:
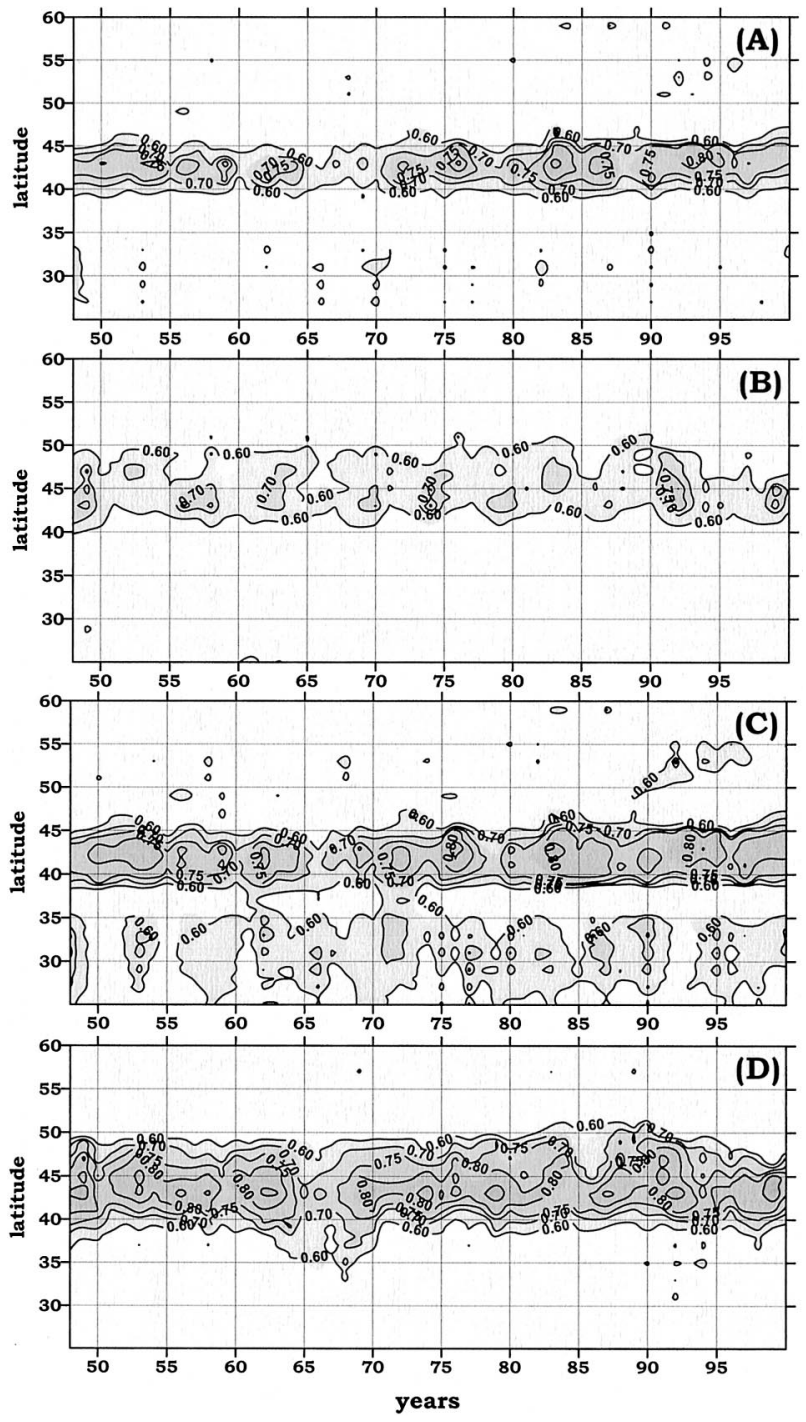

FIG. 10. Temporal evolution from 1948 to 2000 of the correlation coefficients between the values of vector product [Eq. (3)] and synoptic anomalies of (a), (b) surface latent and (c), (d) sensible fluxes along $50^{\circ} \mathrm{W}$ for (a), (c) winter and (b), (d) summer. A correlation of 0.13 is significant at the $95 \%$ level.

$$
\hat{\delta}=\frac{\delta}{\sigma_{Q}}=\frac{\left[\sqrt{\sum\left(Q_{r}^{\prime}-Q^{\prime}\right)^{2}} / n\right]}{\sigma_{Q}},
$$

where $Q_{r}^{\prime}$ is the reconstructed flux anomaly, $Q^{\prime}$ is the observed flux anomaly, $n$ is the number of time steps, $\delta$ is the rms error, and $\sigma_{Q}$ is the standard deviations of interannual anomalies of sea-air flux. In the Gulf Stream area the relative rms error varies primarily within $10 \%$ (values of about $10 \%$ correspond to the flux anomalies of about 6-12 and 10-20 $\mathrm{W} \mathrm{m}^{-2}$ for sensible and latent fluxes, respectively), growing significantly to the south and to the north, where relative rms errors can reach $50 \%-100 \%$. Thus, the area of the potential applicability of the approach can be associated with the region where 


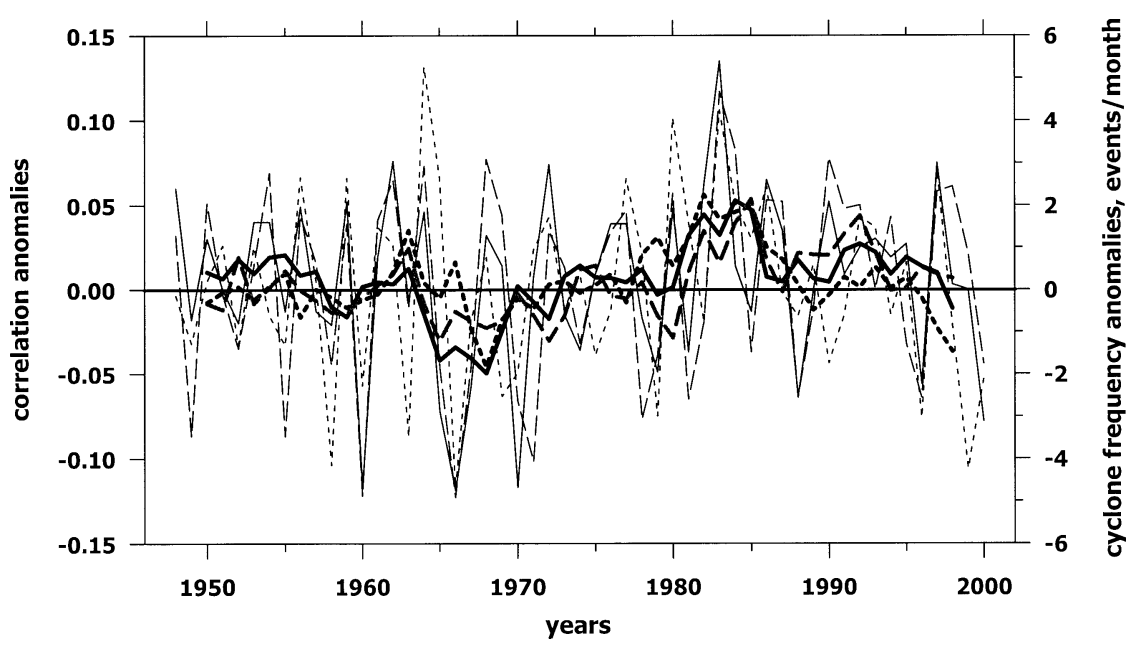

FIG. 11. The time behavior of the winter anomalies of the correlation coefficient between the values of the vector product [Eq. (3)] and synoptic anomalies of surface sensible plus latent heat flux, averaged over the Gulf Stream area (solid lines), anomalies of frequencies of cyclones deeper than $980 \mathrm{hPa}$ (dotted lines), anomalies of correlation coefficients between SLP tendencies and sensible plus latent fluxes (dashed lines). Thin lines correspond to interannual variability, bold lines to a 5-yr running mean.

the relative rms errors in Fig. 13a are smaller than 0.1. This area is limited by the relatively narrow region of the western boundary current of the width of approximately $600-800 \mathrm{~km}$, which, however, is responsible for the highest magnitudes of turbulent fluxes and their most intense synoptic variability. Figure 13b shows the relative rms errors of the reconstruction of the turbulent flux anomalies for the synoptic range from $12 \mathrm{~h}$ to 6 days, that is, for the subsynoptic and synoptic scales on which the mechanism is especially pronounced. For this range the level of error decreases from 2 to 3 times,

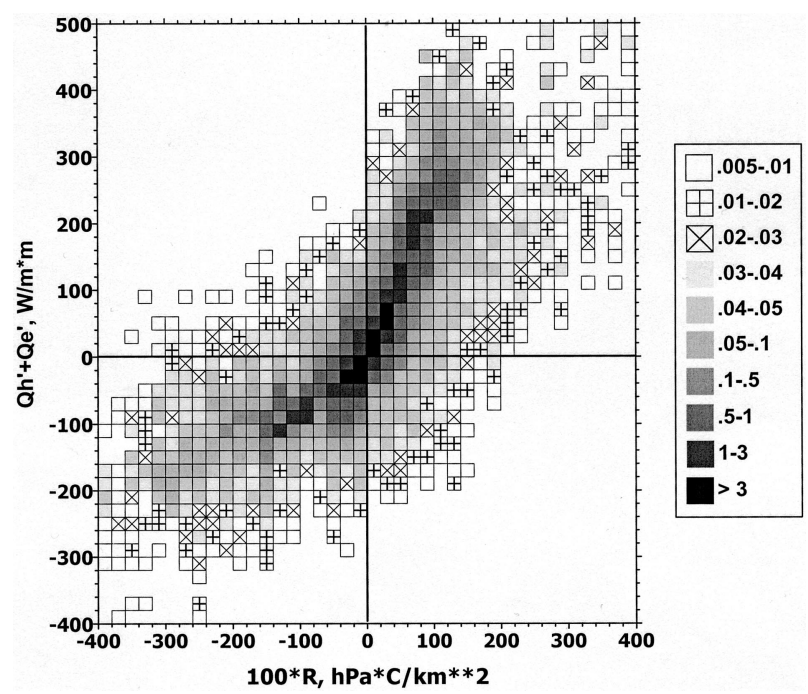

FIG. 12. Scatterplot of the values of the vector product [Eq. (3)] and synoptic anomalies of the sensible plus latent heat flux. Values of the vector product are multiplied by 100 . Occurrence is given in percent. indicating a clear association of the proposed mechanism with synoptic transients.

\section{Sensitivity of the results to the spatial resolution of the SST fields}

One can still reasonably argue that the relatively coarse resolution SST data used in the previous sections, cannot effectively mark strong SST gradients, which are known to have somewhat smaller spatial scales. In order to test the sensitivity of our results to the spatial resolution of the SST fields we analyzed high-resolution MCSST from the NOAA AVHRR. These data have approximately $19-\mathrm{km}$ resolution and are available for 7day periods, that is consistent with the weekly temporal resolution of the OI SST (Reynolds and Smith 1994). The AVHRR data cover the period from 1979 onward. For our comparison we used these data for an 8-yr period from 1989 to 1996. In order to assess the sensitivity of the results to the spatial resolution of SST we applied the analysis presented in sections 3 and 4 to the AVHRR data. Since AVHHR MCSST is originally available on an equal angle grid, for the further computations the data were interpolated onto $0.2^{\circ} \times 0.2^{\circ}$ grid by the

TABLE 1. Estimates of numerical coefficients in Eq. (4) for the computation of sensible and latent heat fluxes from the values of vector product in Eq. (3). The upper numbers are the coefficients, the lower numbers are the coefficient's variances.

\begin{tabular}{crrcrrr}
\hline \hline Coef & \multicolumn{1}{c}{$a_{h 0}$} & \multicolumn{1}{c}{$a_{h}$} & $b_{h}$ & \multicolumn{1}{c}{$a_{e 0}$} & \multicolumn{1}{c}{$a_{e}$} & $b_{e}$ \\
\hline$R>0$ & 0.813 & 0.0361 & 1.432 & 1.181 & 0.0229 & 1.802 \\
& 0.055 & 0.0043 & 0.051 & 0.093 & 0.0041 & 0.051 \\
$R<0$ & -0.317 & -0.0221 & 1.128 & -0.597 & -0.0143 & 1.381 \\
& 0.038 & 0.0048 & 0.027 & 0.037 & 0.0024 & 0.035 \\
\hline
\end{tabular}




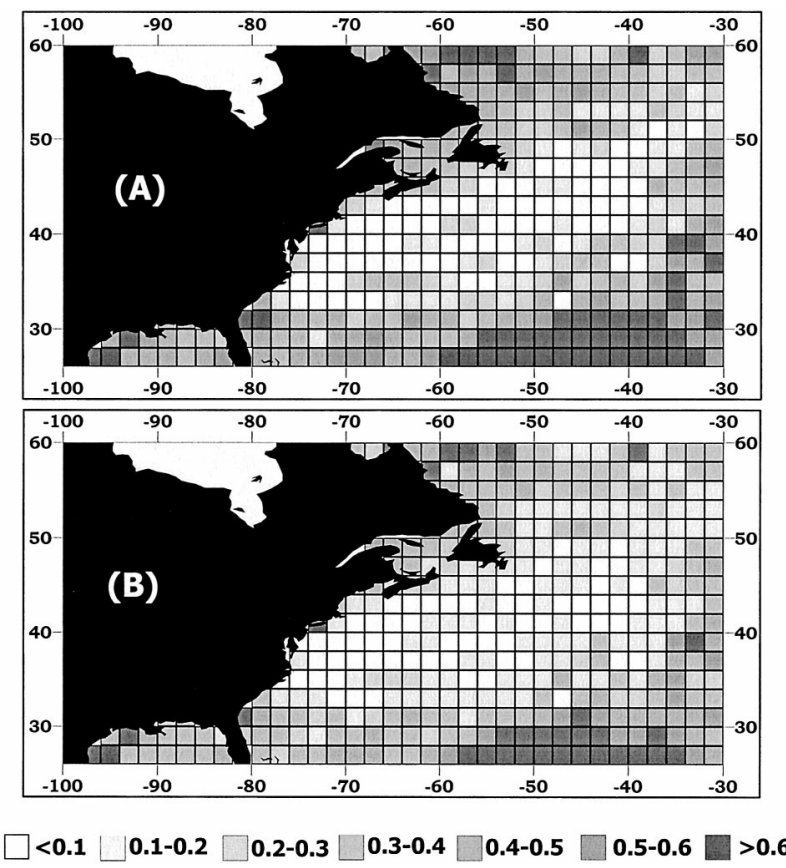

FIG. 13. Relative rms error of the reconstruction of synoptic anomalies of sensible plus latent heat flux ( $\mathrm{W} \mathrm{m}^{-2}$ ) according Eq. (4), computed from (a) the raw data and (b) from the bandpassed data for the range of $12 \mathrm{~h}-6$ days data for the winter season (JFM) of 2001 .

modified method of local procedures of Akima (1970). In order to compute the vector product and to derive the propagation patterns associated with synoptic transients, NCEP-NCAR SLP was interpolated to the same $0.2^{\circ} \times 0.2^{\circ}$ grid. AVHHR MCSST reasonably shows higher SST gradients than those derived from the NCEP-NCAR SST over the Gulf Stream area. In particular, the strongest gradients observed vary from $4^{\circ}$ to $6^{\circ} \mathrm{C}(100 \mathrm{~km})^{-1}$, being $30 \%-50 \%$ larger in comparison to the NCEP-NCAR SST. However, if we consider the zone of the SST gradients higher than $2^{\circ} \mathrm{C}(100$ $\mathrm{km})^{-1}$ (Fig. 7), its location perfectly coincides in both datasets.

Figures $14 \mathrm{a}$, b show the first two EOFs of the vector product computed using AVHHR MCSST for the range of SSCV (2-6 days). They account for $28 \%$ and $25 \%$ of the total variance, being clearly separated from the other EOFs. As for the NCEP-NCAR SST, the first two EOFs clearly show the propagating disturbances along the SST front with spatial patterns being in quadrature and the principal components (not shown) correlated or identical to those presented in Fig. 3 time lags (i.e., implying the same timescales of propagation). For the subsynoptic range of UHFV (0-2 days; no figure shown) the results are also fairly consistent with the analysis, based on the NCEP-NCAR SST (Fig. 8). Propagation of the synoptic anomalies of the values of vector product occurs along the same location of the maximum of the SST gradient, showing no displacement with re- spect to that observed in the NCEP-NCAR data. The shape of the propagating anomalies is more peaked in comparison to Fig. 8. Maximum magnitudes are 10\%$20 \%$ greater than for the NCEP-NCAR SST; however, they are very close to those shown in Fig. 8 already at the distance of $150-200 \mathrm{~km}$ to the south and to the north, where the frontal SST gradients become comparable in the two datasets. This reflects a higher sharpness of the SST front in the AVHHR MCSST data in comparison to the NCEP-NCAR SST. In general, the EOF patterns in Figs. 14a,b exhibit more noisy fields than those derived using the NCEP-NCAR SST in agreement with a higher resolution of these data. We can conclude that the use of high-resolution SST data gives qualitatively the same results as the SST available from the numerical weather prediction (NWP) system (NCEP-NCAR reanalysis).

Figure 14c shows the winter correlation between the values of the vector product, computed for 1996 from the AVHRR MCSST, and synoptic anomalies of air-sea turbulent fluxes taken from the NCEP-NCAR reanalysis. Although the spatial pattern of correlation is considerably more noisy in comparison to those obtained for the NCEP-NCAR SST, the location of the correlation maximum is consistent with that for the NCEPNCAR SST (Fig. 9). It is clearly associated with the Gulf Stream and the beginning of NAC, showing correlation coefficients from 0.6 to 0.82 . Analysis performed for the other seasons (not shown) exhibits qualitatively and quantitatively comparable results with those obtained for the NCEP-NCAR SST.

Nowadays, operational analyses and satellites make SLP and wind fields available at a much higher resolution than T62 available from the NCEP-NCAR reanalysis. Pilot analysis of a higher-resolution SLP data from the ERA-15 reanalysis (T106) and several months of ECMWF operational analyses (T213; not shown here), shows, however, the results that are very close to those obtained using the NCEP-NCAR SLP. Higherresolution products exhibit the most pronounced differences over the land, in particular resolving smallerscale synoptic features associated with a better resolved orography. At the same time, over the oceans, the dominant scales and propagation characteristics of synoptic and subsynoptic transients are quite consistent for the resolutions higher than T50. This is in agreement with the comparison of the climatologies of cyclone life cycle in different datasets (ZGSS), showing that differences in most cyclone characteristics between NCEP-NCAR and ERA-15 are minor in comparison with the effects of the methods of cyclone tracking and temporal resolution of the output $(6,12,24 \mathrm{~h}$; not an actual atmospheric GCM resolution). We will discuss the potentialities of the use of satellite winds in the discussion section.

\section{Summary and discussion}

Analysis of synoptic resolution SLP and turbulent flux data shows that over the Gulf Stream propagating 

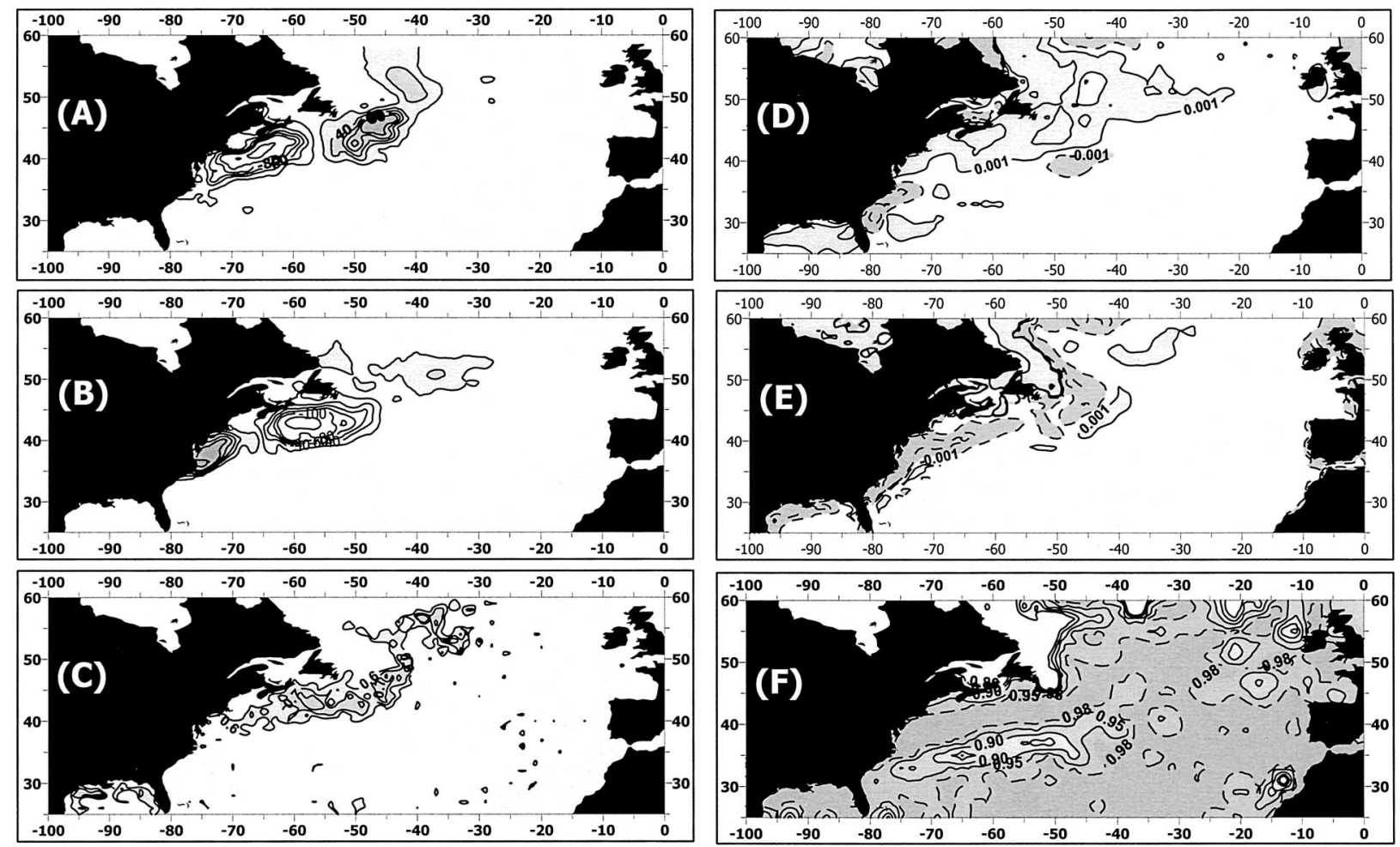

FIG. 14. (a) First and (b) second EOFs of the values of the vector product [Eq. (3)] for the synoptic range of 2-6 days, computed from the NCEP-NCAR SLP and AVHHR MCSST; (c) correlation between the values of vector product [Eq. (1)], computed using AVHHR MCSST and synoptic anomalies of surface sensible plus heat flux for the winter season of 1996; differences in the SST gradients between the periods 1982-2000 and 1948-81, computed from the (d) NCEP-NCAR and (e) GISST; (f) correlation between the values of vector product computed using 6-hourly and monthly mean SST.

atmospheric synoptic transients are clearly associated with the synoptic patterns of turbulent fluxes traveling according to the same principle and showing spatial and temporal scales, which are consistent with atmospheric cyclones. In a cyclones' rear, advection of the cold and dry Arctic air is roughly orthogonal to the SST front, resulting in an increase of sea-air heat fluxes. Alternatively, in the forward areas of propagating cyclones, advection of the tropical air over relatively cold underlying water results in the negative synoptic anomalies of turbulent fluxes. We proposed a simple approach for the parameterization of surface ocean-atmosphere turbulent fluxes on synoptic timescales in the frontal midlatitudinal zones. It is based on the joint consideration of the geostrophic winds and sea surface temperature gradients, whose interaction largely controls the coldair and warm-air outbreaks in the vicinity of the SST fronts. The vector product of the geostrophic wind and the vector characterizing the sharpness of the surface temperature gradient is suggested as a quantitative measure of the intensity of air-sea turbulent fluxes on a synoptic scale. Simple relationships between this vector product and synoptic anomalies of surface sensible and latent heat fluxes allow us to get the first guess about the instant spatial distribution of surface fluxes using SST and SLP fields, which are more accurate and more easily available on synoptic space-time resolution than the other basic surface parameters (wind, air temperature, humidity). The applicability of the proposed approach is restricted by the relatively narrow frontal zone. However, this area is characterized by $5-10$ times higher (in comparison to the open ocean regions) mean values of fluxes and the highest magnitudes of their synoptic and interannual variability and it is crucially important for the quantitative description of sea-air interaction in the North Atlantic.

A simplified approach proposed here is consistent with the mechanisms driving synoptic-scale sea-air interaction processes. Cayan (1992a,b) noted that surface air temperature and moisture are both dependent on the meridional component of wind even on monthly timescales, which implies the dominant role of the thermodynamic characteristics of the advected air masses and the intensity of the advection (i.e., wind components orthogonal to the SST front) in the turbulent flux anomalies. Behringer et al. (1979) suggested a relationship between the sea-air temperature difference and the wind stress as a feedback driving an idealized model in which the wind-forced changes of the Gulf Stream were coordinated with the intensity of sea-air heat exchange. Our work provides a simple parameter that allows for the quantitative estimation of the role of this mechanism 
on synoptic timescales. Thus, qualitatively, the proposed parameterization is quite effective for the synoptic and subsynoptic temporal scales, on which the propagating cyclones over a slowly varying SST front (with respect to the cyclone propagation) represent the dominant mode of the variability. In general, our approach can be used for the areas outside of the main storm track over locally strong SST gradients. Results of the Structure des Echanges Mer-Atmosphere, Proprietes des Heterogeneites Oceaniques: Researche Experimentale (SEMAPHORE) experiment in the eastern Atlantic (e.g., Eymard et al. 1999) or of the Frontal Air-Sea Interaction Experiment (FASINEX; Friehe et al. 1991) show that in the case of the advection across the frontal zone, turbulent fluxes are changing according to the same principle as described above. However, only in the areas of the western boundary currents and intensive storm tracks does this mechanism appear to be dominant in the synoptic variability of sea-air fluxes. Nevertheless, these are regions of the western boundary currents, where surface turbulent fluxes demonstrate the largest magnitudes and the highest synoptic-scale variability. Even in the other regions of locally strong SST gradients this mechanism represents a secondary mode, which does not account for the major factors responsible for the variability of surface fluxes.

An important question is the quantitative robustness of the obtained relationships. Surface fluxes from the NCEP-NCAR reanalysis (as well as from the other reanalyses) may be biased in the Gulf Stream area due to the problems with the flux parameterizations and the data assimilation input. In this context the question about the reliability of the obtained relationships is of a great importance. Since we are dealing with synoptic anomalies of fluxes [Eq. (1)] and not with the climate means, systematic biases in monthly means (if any) will not qualitatively change the results. However, different methods of the surface flux computations can result in different magnitudes of synoptic anomalies of turbulent fluxes and, therefore, quantitatively change numerical values of the coefficients in [Eq. (4)]. Thus, further validation of the approach using in situ measurements of the air-sea turbulent fluxes is desirable. However, there are only few direct measurements of air-sea fluxes in this highly variable area. Moreover, they are primarily collected under small and moderate winds and not under the storm conditions, which are typical for the back parts of cyclones during the cold-air outbreaks.

The use of the alternative high-resolution AVHHR MCSST for a better depiction of surface temperature gradients demonstrates good qualitative agreement with the coarser resolution data. High correlation with the flux anomalies shown in Fig. 14c, demonstrates that the mechanism is also valid for the high-resolution SST data. However, this comparison suffers from the inconsistency of the spatial resolution of fluxes taken from NCEP-NCAR reanalysis and satellite SST. Obviously, MCSST accounts for smaller-scale features, which are not present in the relatively coarse resolution surface flux fields. In order to make a perfect validation, one should use the flux fields consistent in terms of resolution with that of MCSST. Such flux products are not yet available. At present the most advanced satellite flux product based on SSM/I data [Hamburg Ocean-Atmosphere Parameters from Satellites (HOAPS); Schulz et al. 1997] provides $1^{\circ}-2^{\circ}$ daily fields, which are, in terms of resolution, close to those available from NWP. At the same time, this approach can be used for the regional short-term reconstructions of surface fluxes derived from remotely sensed data, characterized by the incomplete sampling (e.g., Miller and Katsaros 1992).

For our analysis we used the NCEP-NCAR SST, represented by the OI SST starting from 1982 and based on EOF-reconstructed temperature fields (Reynolds and Smith 1994) prior to 1982. An interesting question is to what extent this definite break in the processing of the SST data could influence the results. Figure 14d shows the difference in the magnitude of the winter SST gradients between the period 1982-2000 and 1948-81, derived from the NCEP-NCAR SST. Over the Gulf Stream south of $37^{\circ} \mathrm{N}$ there is a tendency of weakening of the SST gradient, while in the area between $70^{\circ}$ and $40^{\circ} \mathrm{W}$ there has been a slight increase of the SST gradient. In comparison to the mean values of the SST gradient (Fig. 7a), the differences observed vary within $2 \%-3 \%$ of mean values. For the comparison we used an alternative $1^{\circ}$ resolution Global Sea Ice and Sea Surface Temperature dataset (GISST), which is less influenced by the inhomogeneities in data processing (Parker et al. 1995). The same differences, computed from GISST data are shown in Fig. 14e. Note, however, that the GISST dataset is available on monthly resolution only and, thus, this comparison represents a very rough assessment of the effect. GISST shows weakening of the SST gradients in the area south of $37^{\circ} \mathrm{N}$ in agreement with NCEP-NCAR SST. However, in the area of the Gulf Stream and the North Atlantic Current (NAC) in the open ocean, GISST primarily indicates a negative difference in contrast to the weakly positive tendencies reported by NCEP-NCAR SST. Thus, the change in the SST processing in 1982 in NCEP-NCAR reanalysis can result in the slight increase of the magnitude of the SST gradients. However, when we reprocessed the computations of the vector product and its relationships with sea-air flux anomalies for these two periods, the results were quantitatively very comparable and no statistically significant differences were identified.

In this sense, an interesting question to address is how much the proposed measure of the intensity of synoptic sea-air interaction is influenced by the changes in SST and to what extent it is dependent on the atmospheric dynamics. Figure 14f shows the correlation coefficients between the vector product, computed using 6-hourly SLP and SST data and using 6-hourly SLP data in combination with the monthly mean SST. Extremely high correlation (more than 0.95 for most locations, even 
where the mechanism is not expected to be working) suggests that the atmospheric dynamics is the dominant contributor to the mechanism proposed. A slight decrease of the correlation along the south periphery of the Gulf Stream in the area of its recirculation is associated with the SST disturbances in the recirculation zone, which are partly resolved in high-resolution data and are not present in monthly fields. The existence of the strong surface temperature gradient is extremely important for the maintenance of the mechanism, but its variability does not strongly influence the results.

Thus, in the future it will be important to investigate the potentialities of satellite winds, which are now available on synoptic resolution with high accuracy by courtesy of the SSM/I, the first and second European Remote Sensing Satellites (ERS-1/2), and the NASA Scatterometer (NSCAT) missions. On one hand, these data are known to depict synoptic features of the wind fields quite reliably (e.g., Chelton 2001). In particular, Liu et al. (2001) have shown the applicability of the QuickSCAT daily wind fields with $25-\mathrm{km}$ spatial resolution for the diagnostics of hurricanes. On the other hand, extensive analysis requires high temporal resolution (better than daily) in an even higher degree than the fine spatial resolution. However, the production of the satellite wind fields without data gaps and with high spatial resolution results in temporal averaging, and, thus, decreases temporal resolution. The same is valid for the high-resolution SST data discussed above. We think, that a more optimistic perspective is connected with high-resolution NWP wind products, based on the best performed atmospheric GCMs and the assimilation of satellite winds. These products will merge the advantages of modeling and satellite technologies. Concerning the potentialities of remote sensing, an additional space-based parameter that can help to quantify atmospheric synoptic processes, is the satellite cloudiness, which effectively marks the circulation patterns in the midlatitudinal cyclones.

Of great interest is the applicability of this approach to the other areas of intense synoptic variability of surface turbulent fluxes associated with atmospheric cyclones. First of all, these are the Kuroshio region and some local areas in the Southern Ocean (e.g., Agulhas Current). A similar approach can be used for the consideration of synoptic variability of surface turbulent fluxes, associated with the outbreaks over the midlatitudinal coastlines and ice margins. Actually the results shown in Fig. 14f imply the dominant role of the atmospheric dynamics in comparison to the short-period variability of the temperature of the underlying surfaces. According to the case studies (Overland et al. 1983; Bane and Osgood 1989; Konrad and Colucci 1989; Okland 1998) the processes over coastlines and ice margins are similar to those observed over the SST fronts and the magnitudes of synoptic variability in sea-air turbulent fluxes can be even higher. For this purpose, SST fields can be combined with the skin temperatures over the land and ice cover, that will allow us to quantify the near-surface temperature gradients. Gulev et al. (2002) suggested merging SST with the skin temperatures over land and considered the gradients in surface temperature fields. These gradients were found to be highly correlated with the intensity of atmospheric synoptic processes in the North Atlantic.

Synoptic-scale resolution SLP and SST fields are available for longer periods than the other parameters. Thus, the 12-hourly resolution SLP archives are collected for a centennial continuity (e.g., Trenberth and Paolino 1980). Gulf Stream charts, which can effectively serve for the proposed analysis are also produced for the period of the last several decades. Thus, the relationships of the kind of Eq. (4) derived for the periods of availability of these data can be used for the reconstruction of synoptic variability of surface fluxes in the Gulf Stream area for long periods. The other possible application of our approach is the diagnostics of the model results, obtained with atmospheric and high-resolution coupled GCMs, which effectively resolve the propagating atmospheric transients (e.g., Alexander and Scott 1997). Limited-area higher-resolution models already provide insights about the role of the SST front in driving atmospheric cyclones (Giordani and Caniaux 2001). The use of this approach for the analysis of model results can help to identify the role of different processes in synoptic sea-air interaction.

Acknowledgments. We thank Glenn White of NCEP (Camp Spring, Maryland), who made available the NCEP-NCAR reanalysis data for us. The AVHRR MCSST data were made available by Tim Liu of JPL (Pasadena, California). Suggestions and criticism from two anonymous reviewers helped to improve the manuscript and are greatly appreciated. We thank Dick Reynolds and Diane Stokes of NCEP (Camp Spring) for useful discussions and their help with processing the SST data, and Eberhard Ruprecht of IFM (Kiel, Germany) for the discussions about physical mechanisms of sea-air interaction. This work is supported by Deutsche Forschungsgemeinschaft Sonderforschungsbereich SFB-460 and the Ministry of Industry and Science of Russian Federation under the "World Ocean" National Programme. OZ benefited from the support of "Nordrhein-Westfaelische Akademie der Wissenschaften," Dusseldorf, Germany.

\section{REFERENCES}

Akima, H., 1970: A new method of interpolation and smooth curve fitting based on local procedures. J. Appl. Comput. Math., 17, 589-602.

Alexander, M. A., and J. D. Scott, 1997: Surface flux variability over the North Pacific and North Atlantic Oceans. J. Climate, 10, 2963-2977.

Ayrault, F., F. Lalaurette, A. Joly, and C. Loo, 1995: North Atlantic ultra high frequency variability. Tellus, 47A, 671-696.

Bane, J. M., and K. E. Osgood, 1989: Wintertime air-sea interaction 
processes across the Gulf Stream. J. Geophys. Res., 94 (C8), $10755-10772$.

Behringer, D., L. Regier, and H. Stommel, 1979: Thermal feedback on the wind stress as a contributing cause of the Gulf Stream. J. Mar. Res., 37, 699-709.

Blackmon, M. L., Y. H. Lee, J. M. Wallace, and H. H. Hsu, 1984 : Horizontal structure of $500 \mathrm{mb}$ height fluctuations with long, intermediate and short time scales. J. Atmos. Sci., 41, 961-979.

Brown, J. W., O. B. Brown, and R. H. Evans, 1993: Calibration of Advanced Very High Resolution Radiometer infrared channels: A new approach to nonlinear correction. J. Geophys. Res., 98, 18 257-18 268 .

Cayan, D., 1992a: Latent and sensible heat flux anomalies over the Northern Oceans: The connection to monthly atmospheric circulation. J. Climate, 5, 354-369.

$\ldots, 1992$ b: Variability of latent and sensible heat fluxes estimated using bulk formulae. Atmos.-Ocean, 30, 1-42.

$\ldots, 1992 \mathrm{c}$ : Latent and sensible heat flux anomalies over the Northern Oceans: Driving the sea surface temperature. J. Phys. Oceanogr., 22, 859-881.

Chang, C.-B., D. J. Perkey, and W.-D. Chen, 1987: Observed dynamic structure of an intense oceanic cyclone. Mon. Wea. Rev., 115, 1127-1139.

Chao, S.-Y., 1992: An air-sea interaction model for cold-air outbreaks. J. Phys. Oceanogr., 22, 821-842.

Chelton, D., 2001: Scatterometer based assessment of surface wind field analysed from the European Centre for Medium-Range Weather Forecasts. Proc. WCRP/SCOR Workshop on Intercomparison and Validation of Ocean-Atmosphere Flux Fields, Washington, DC, WCRP/SCOR, WMO/TD-1083, 135-141.

da Silva, A. M., C. C. Young, and S. Levitus, 1994a: Algorithms and Procedures. Vol. 1, Atlas of Surface Marine Data 1994, NOAA Atlas NESDIS 6, 83 pp.

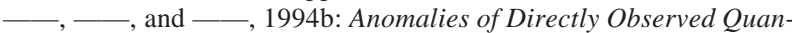
tities. Vol. 2, Atlas of Surface Marine Data 1994, NOAA Atlas NESDIS 7, 416 pp.

- - - and - 1994c: Anomalies of Heat and Momentum Fluxes. Vol. 3, Atlas of Surface Marine Data 1994, NOAA Atlas NESDIS 8, 411 pp.

,-- , and —_, 1994d: Anomalies of Fresh Water Fluxes. Vol. 4, Atlas of Surface Marine Data 1994, NOAA Atlas NESDIS 9 , 308 pp.

$\ldots, \ldots$, and 1994e: Anomalies of Miscellaneous Derived Quantities. Vol. 5, Atlas of Surface Marine Data 1994, NOAA Atlas NESDIS 10, 416 pp.

—_ — - and ——, 1994f: Heat Flux Sensitivity to Sea Surface Temperature. Vol. 6, Atlas of Surface Marine Data 1994, NOAA Atlas NESDIS 12, 80 pp.

Dickson, R. R., and J. Namias, 1976: North American influences on the circulation and climate of the North Atlantic sector. Mon. Wea. Rev., 104, 1255-1265.

Duchon, C. E., 1979: Lanczos filtering in one and two dimensions. J. Appl. Meteor., 18, 1016-1022.

Eymard, L., and Coauthors, 1999: Surface fluxes in the North Atlantic current during CATCH/FASTEX. Quart. J. Roy. Meteor. Soc., 125, 3563-3599.

Friehe, C. A., and Coauthors, 1991: Air-sea fluxes and surface layer turbulence around a sea surface temperature front. J. Geophys. Res., 96 (C5), 8593-8609.

Gibson, J. K., P. Kallberg, S. Uppala, A. Nomura, A. Hernandes, and A. Serrano, 1997: ERA description. ECMWF Reanalysis Project Report Series, Vol. 1, ECMWF, Reading, United Kingdom, 77 pp.

Giordani, H., and G. Caniaux, 2001: Sensitivity of cyclogenesis to sea surface temperature in the northwestern Atlantic. Mon. Wea. Rev., 129, 1273-1295.

Grigoriev, S., S. K. Gulev, and O. Zolina, 2000: Software for storm tracking and atmospheric cyclone analysis. Eos, Trans. Amer. Geophys. Union, 81, 170-171.

Gulev, S. K., 1997: Climate variability of the intensity of synoptic processes in the North Atlantic midlatitudes. J. Climate, 10, 574592.

and J. Tonkacheev, 1996: Investigation of the ocean-atmosphere interaction in the North Atlantic mid-latitude frontal zone. The Air-Sea Interface, M. Donelan, W. Hui, and W. Plant, Eds., RSMAS, 535-542.

_, O. Zolina, and S. Grigoriev, 2001: Extratropical cyclone variability in the Northern Hemisphere winter from the NCEPNCAR reanalysis data. Climate Dyn., 17, 795-809.

— - T. Jung, and E. Ruprecht, 2002: Climatology and interannual variability in the intensity of synoptic-scale processes in the North Atlantic from the NCEP-NCAR reanalysis data. J. Climate, 15, 809-828.

Harnack, R. P., and A. J. Broccoli, 1979: Associations between sea surface temperature gradient and overlying mid-tropospheric circulation in the North Pacific region. J. Phys. Oceanogr., 9, 1232 1242.

Hoskins, B. J., and P. D. Sardeshmukh, 1987: Transient eddies and the seasonal mean rotational flow. J. Atmos. Sci., 44, 328-338. , and P. J. Valdes, 1990: On the existence of storm tracks. J. Atmos. Sci., 47, 1854-1864.

Hsu, S. A., 1983: On the growth of a thermally modified boundary layer by advection of warm air over a cooler sea. J. Geophys. Res., 88 (C1), 771-774.

Iwasaka, N., and J. M. Wallace, 1995: Large-scale air-sea interaction in the Northern Hemisphere from a view point of variations of surface heat flux by SVD analysis. J. Meteor. Soc. Japan, 73, 781-794.

Josey, S., E. C. Kent, and P. K. Taylor, 1999: New insights into the ocean heat budget closure problem from analysis of the SOC air-sea flux climatology. J. Climate, 12, 2856-2880.

Kalnay, E., and Coauthors, 1996: The NCEP/NCAR 40-Year Reanalysis Project. Bull. Amer. Meteor. Soc., 77, 437-471.

Kistler, R., and Coauthors, 2001: The NCEP/NCAR 50-Year Reanalysis: Monthly means CD-ROM and documentation. Bull. Amer. Meteor. Soc., 82, 247-267.

Konrad, C. E., and S. J. Colucci, 1989: An examination of extreme cold-air outbreaks over eastern North America. Mon. Wea. Rev., 117, 2687-2700.

Lambert, S., 1996: Intense extratropical Northern Hemisphere winter cyclone events: 1899-1991. J. Geophys. Res., 101, 21 319-21 325.

Lanczos, C., 1956: Applied Analysis. Prentice-Hall, 539 pp.

Lanzante, J. R., 1983: A further assessment of the association between sea surface temperature gradient and the overlying midtropospheric circulation. J. Phys. Oceanogr., 13, 1971-1974.

Liu, W. T., H. Hu, Y. T. Song, and W. Tang, 2001: Improvement of scatterometer wind vectors-Impact on hurricane and coastal studies. Proc. WCRP/SCOR Workshop on Intercomparison and Validation of Ocean-Atmosphere Flux Fields, Washington, DC, WCRP/SCOR, WMO/TD-1083, 197-200.

Long, P. E., cited 1988: Atmospheric boundary layer and processes at the earth's surface. [Available online at http://sgi62.wwb. noaa.gov.]

Mak, M., 1998: Influence of surface sensible heat flux on incipient marine cyclogenesis. J. Atmos. Sci., 55, 820-834.

Miller, D. K., and K. B. Katsaros, 1992: Satellite derived surface latent heat fluxes in a rapidly intensifying marine cyclone. Mon. Wea. Rev., 120, 1093-1107.

Murray, R. J., and I. Simmonds, 1991: A numerical scheme for tracking cyclone centres from digital data. Part I: Development and operation of the scheme. Aust. Meteor. Mag., 39, 155-166.

Neiman, P. J., M. A. Shapiro, E. G. Donall, and C. W. Kreitzberg, 1990: Diabatic modification of an extratropical marine cyclone warm sector by cold underlying water. Mon. Wea. Rev., 118, 1576-1590.

Nuss, W. A., and R. A. Anthes, 1987: A numerical investigation of low-level processes in rapid cyclogenesis. Mon. Wea. Rev., 115, 2728-2743.

Okland, H., 1998: Modification of frontal circulations by surface heat flux. Tellus, 50A, 211-218. 
Overland, J. E., R. M. Reynolds, and C. H. Pease, 1983: A model of the atmospheric boundary layer over the marginal ice zone. $J$. Geophys. Res., 88 (C5), 2836-2840.

Parker, D. E., C. K. Folland, and M. Jackson, 1995: Marine surface temperature: Observed variations and data requirements. Climatic Change, 31, 559-600.

Pettersen, S., D. L. Bradbury, and K. Pedersen, 1962: The Norwegian cyclone models in relation to heat and cold sources. Geophys. Publ., 24, 243-280.

Reddy, N. C., and S. Raman, 1994: Observations of a mesoscale circulation over the Gulf Stream region. Global Atmos. Ocean Syst., 2, 21-39.

Reynolds, R. W., and T. M. Smith, 1994: Improved global sea surface temperature analyses using optimum interpolation. J. Climate, 7, 929-948.

Schulz, J., J. Meywerk, S. Ewald, and P. Schlüssel, 1997: Evaluation of satellite-derived latent heat fluxes. J. Climate, 10, 2782-2795.

Sethuraman, S., A. J. Riordan, T. Holt, M. Stunder, and J. Hinman, 1986: Observations of the marine boundary layer thermal structure over the Gulf Stream during a cold-air outbreak. J. Climate Appl. Meteor., 25, 14-21.

Trenberth, K. E., and D. A. Paolino, 1980: The Northern Hemisphere sea-level pressure data set: Trends, errors and discontinuities. Mon. Wea. Rev., 108, 855-872.

Wai, M.-K. M., 1988: Modelling the effects of the spatially varying sea surface temperature on the marine atmospheric boundary layer. J. Appl. Meteor., 27, 5-19.

_ _ and S. A. Stage, 1989: Dynamical analyses of marine atmospheric boundary layer near the Gulf Stream oceanic front Quart. J. Roy. Meteor. Soc., 115, 29-44.

WGASF Group, 2000: Intercomparison and validation of ocean-atmosphere energy flux fields. Final Report, Joint WCRP/SCOR Working Group on Air-Sea Fluxes, WMO, Geneva, Switzerland, 305 pp. [Available online at http://www.soc.soton.ac.uk/JRD/ MET/WGASF.]

Yau, M. K., and M. Jean, 1989: Synoptic aspects and physical processes in the rapidly intensifying cyclone of 6-8 March 1986. Atmos.-Ocean, 27, 59-86.

Zolina, O., and S. K. Gulev, 2002: Improving accuracy of mapping cyclone numbers and frequencies. Mon. Wea. Rev., 130, 748759.

Zorita, E., V. Kharin, and H. von Storch, 1992: The atmospheric circulation and sea surface temperature in the North Atlantic area in winter: Their interaction and relevance for Iberian precipitation. J. Climate, 5, 1097-1108. 